UNIVERSIDADE DE SÃO PAULO

FACULDADE DE MEDICINA DE RIBEIRÃO PRETO

MARINA DIAS LELIS MONTEIRO

A comunicação no contexto das visitas domiciliares: uma investigação das percepções de profissionais e usuários na Estratégia Saúde da Família 


\title{
A comunicação no contexto das visitas domiciliares: uma investigação das percepções de profissionais e usuários na Estratégia Saúde da Família
}

\author{
Versão Original
}

Dissertação apresentada ao Programa de Pós-Graduação em Saúde na Comunidade da Faculdade de Medicina de Ribeirão Preto da Universidade de São Paulo para a obtenção do título de Mestre em Ciências.

Linha de Pesquisa: Estudos em Atenção Primária e Saúde da Família.

Orientador: Prof. Dr. Gustavo Salata Romão 
Autorizo a reprodução e divulgação total ou parcial deste trabalho, por qualquer meio convencional ou eletrônico, para fins de estudo e pesquisa, desde que citada a fonte.

\section{Catalogação da Publicação}

Preparada para a Biblioteca do Serviço de Documentação

Faculdade de Medicina da Ribeirão Preto da Universidade de São Paulo

Lelis, Marina Dias Monteiro

A comunicação no contexto das visitas domiciliares: uma investigação das percepções de profissionais e usuários na Estratégia Saúde da Família. Ribeirão Preto, 2018.

66p. : il.

Dissertação de Mestrado, apresentada à Faculdade de Medicina de Ribeirão Preto da Universidade de São Paulo. Área de concentração: Saúde na Comunidade.

Orientador: Romão, Gustavo Salata.

1. Comunicação em Saúde. 2. Estratégia Saúde da Família. 3. Visita Domiciliar. 4. Habilidades Sociais. 5. Ação Comunicativa. 
Nome: LELIS, Marina Dias Monteiro

Título: A comunicação no contexto das visitas domiciliares: uma investigação das percepções de profissionais e usuários na Estratégia Saúde da Família.

Dissertação apresentada ao Programa de Pós-Graduação em Saúde na Comunidade da Faculdade de Medicina de Ribeirão Preto da Universidade de São Paulo para a obtenção do título de Mestre em Ciências.

Aprovado em:

Banca Examinadora

Prof.(a) Dr.(a):

Instituição:

Julgamento:

Prof.(a) Dr.(a):

Instituição:

Julgamento:

Prof.(a) Dr.(a):

Instituição:

Julgamento: 


\section{DEDICATÓRIA}

Ao meu esposo Luiz Eduardo, com amor e gratidão por me encorajar e me apoiar incondicionalmente ao longo desta minha trajetória de grande crescimento.

Aos meus pais, Maria do Carmo e Fernando, e irmão Gaspar, pelo amor, incentivo e ensinamentos transmitidos ao longo de toda minha vida. 


\section{AGRADECIMENTOS}

Ao meu orientador, Prof. Gustavo, pela disponibilidade, dedicação e grande aprendizado ao longo desta trajetória. Agradeço pelo incentivo e por acreditar em meus conhecimentos e potencial.

À querida Profa. Sheyla, que colaborou grandemente e esteve presente durante toda a elaboração e execução deste projeto. Obrigada pelo carinho, dedicação, disponibilidade, aprendizado e por toda experiência transmitida na área de comunicação.

Aos participantes da pesquisa, profissionais de saúde e usuários, que se disponibilizaram em compartilhar suas vivências e percepções.

Às minhas amigas Tatiana, Angélica, Rosana e Rosi por me encorajarem, no início, a traçar este caminho de grande conhecimento.

Às meus queridos amigos e amigas conquistados na Pós-Graduação, Mary, Mariana, Bianca, Luana, Thamires, Samara, Fernando, Rinaldo, Nayara e Belkiss. Obrigada pela amizade e carinho, por compartilhamos importantes momentos e boas risadas.

Ao corpo docente do Programa de Pós-Graduação em Saúde na Comunidade pela aprendizagem e conhecimentos adquiridos.

Aos funcionários do Departamento de Medicina Social FMRP - USP, pela dedicação e serviços prestados.

Ao meu esposo, meus pais e irmão, pelo amor incondicional, acolhimento, apoio e grande incentivo. Minha eterna gratidão! 


\section{RESUMO}

Lelis Marina Dias Monteiro. A comunicação no contexto das visitas domiciliares: uma investigação das percepções de profissionais e usuários na Estratégia Saúde da Família. 2018. 66f. Dissertação (Mestrado em Ciências) - Faculdade de Medicina de Ribeirão Preto, Universidade de São Paulo, Ribeirão Preto, 2018.

O presente trabalho teve como objetivo investigar como a comunicação se processa no contexto das visitas domiciliares sob a ótica dos profissionais de saúde e usuários de seis Núcleos Saúde da Família (NSF) do Município de Ribeirão Preto-SP. Participaram deste estudo 19 profissionais de saúde, sendo eles, médicos, enfermeiros e agentes comunitários, e 29 usuários. Os dados foram coletados no período de setembro de 2016 a abril de 2017, por meio de inserção no campo, observação participante $(\mathrm{OP})$ e realização das entrevistas. Após a transcrição dos dados, estes foram analisados conforme o método de Análise de Conteúdo de Bardin e interpretados à luz das contribuições do agir comunicativo de J. Habermas. Como resultado, emergiram duas categorias: 1. "Atuação profissional no contexto das visitas domiciliares" e 2. "O processo de comunicação nas visitas domiciliares". Diferentes aspectos positivos foram atribuídos conferidos ao processo de $\mathrm{VD}$, tanto pelos usuários quanto pelos profissionais. Todos os entrevistados consideram as visitas espaços de acolhimento, criação de vínculo, confiança e oferta de acesso aos serviços de saúde. Para os profissionais entrevistados, adentrar no espaço das famílias confere um novo significado aos atendimentos, a qual possibilita a obtenção de informações adicionais sobre a vida dos usuários. Com relação às particularidades da atuação profissional, observamos que as atuações possuem significados diferentes para cada membro da equipe. Estas diferenças repercutem no processo de comunicação profissional-usuário estabelecido durante a VD e se relacionam ao tipo e objetivo da visita. Nenhum profissional relatou dificuldades para se comunicar e atribuíram todas as dificuldades de comunicação a aspectos relacionados aos usuários. A partir da Teoria do Agir Comunicativo, concluímos que os profissionais assumem posturas que evidenciam tanto o uso da razão instrumental quanto da razão comunicativa, com o predomínio da primeira nas atividades desempenhadas nas VD. Este tipo de interação comunicativa pode apresentar como consequências dificuldades na construção de vínculos, na compreensão do contexto sociocultural no qual o usuário está inserido e na aquisição de autonomia pelo paciente. No Brasil, a grande maioria das instituições de ensino ainda se apoia na razão instrumental técnico-científica que utiliza a comunicação basicamente para transmitir informações. Os profissionais formados nessa lógica tendem a reproduzir este modelo nas relações profissionais. Diante do exposto, salientamos que a comunicação efetiva nas VD requer treinamento direcionado às habilidades de comunicação na formação dos profissionais de saúde, sendo este espaço propício para o ensino-aprendizagem dessas habilidades.

Palavras-chave: Comunicação em Saúde. Estratégia Saúde da Família. Visita Domiciliar. Habilidades Sociais. Ação Comunicativa. 


\begin{abstract}
Lelis, M. D. M. Communication in the context of home visits: an investigation of the perceptions of professionals and users in the Family Health Strategy. 2018. 66f. Dissertação (Mestrado) -Faculdade de Medicina de Ribeirão Preto, Universidade de São Paulo, 2018.
\end{abstract}

The present research had as objective to investigate how the communication takes place in the context of home visits from the perspective of health professionals and users of six Family Health Centers in Ribeirão Preto-SP. Participated in this study 19 health professionals, among them doctors, nurses and community agents, and 29 users. Data were collected from September 2016 to April 2017, through field insertion, participant observation (PO) and interviews. After the data were transcribed, they were analyzed according to the Bardin Content Analysis method and interpreted in the light of the contributions of J. Habermas's Communicative Action. As a result, two categories emerged: 1. "Professional work in the context of home visits" and 2. "The communication process in home visits". Different positive aspects were attributed to the home visit process, both by users and professionals. All the interviewees consider that the visits provide host spaces, bonding, trust and offer of access to health services. For professionals interviewed, entering the family space gives a new meaning to the services, which enables the collection of additional information about the life of the users. With regard to the particularities of the professional performance, we observed that it has different meanings for each member of the health team. These differences have repercussions on the professional-user communication process established during the home visit and relate to the type and purpose of the visit. No professional reported difficulties to communicate and attributed all of them to aspects related to users. From the Theory of Communicative Action, we conclude that professionals assume positions that evidence both the use of instrumental reason and communicative reason, with the predominance of the former in the activities performed in the home visit. This type of communicative interaction may have as consequence difficulties in building bonds, in understanding the sociocultural context in which the user is inserted and in the acquisition of autonomy by the patient. In Brazil, the great majority of educational institutions still rely on the technical-scientific instrumental reason that uses communication basically to transmit information. Professionals trained in this logic tend to reproduce this model in professional relationships. About that, we emphasize that effective communication in the home visit requires training directed to communication skills in the training of health professionals, being this space conducive to teaching-learning these skills.

Keywords: Health Communication. Family Health Strategy. Home visit. Social skills. Communicative Action. 


\section{SUMÁRIO}

1 INTRODUÇÃ

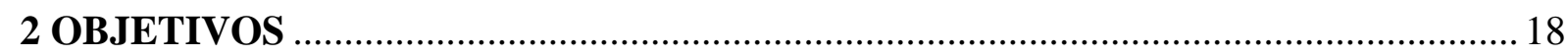

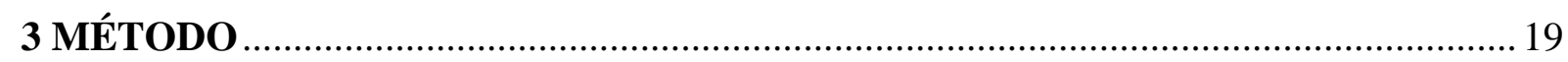

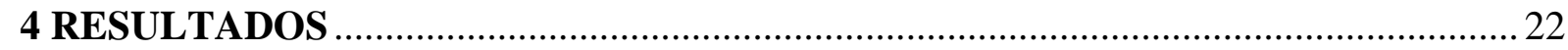

4.1 CARACTERIZAÇÃO DOS SUJEITOS ENTREVISTADOS ................................... 22

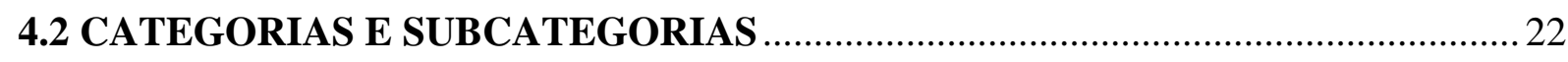

4.2.1 Categoria 1 “Atuação profissional no contexto das visitas domiciliares" ............... 22

4.2.1.1 Subcategoria "A VD como espaço de interação entre a equipe de saúde e a

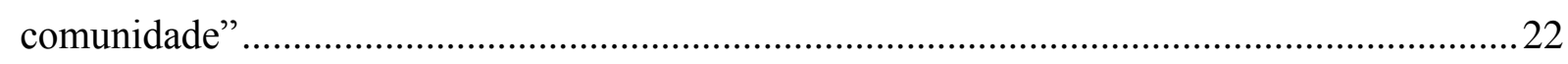

4.2.1.2 Subcategoria "Particularidades na atuação profissional nas VD" .............................. 24

4.2.2 Categoria 2 "O processo de comunicação nas visitas domiciliares” ........................ 31

4.2.2.1 Subcategoria "A comunicação na relação entre usuários e os profissionais da equipe

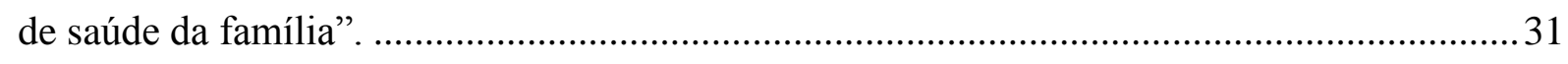

4.2.2.2 Subcategoria "Facilitadores e barreiras da comunicação durante as VD: percepção dos

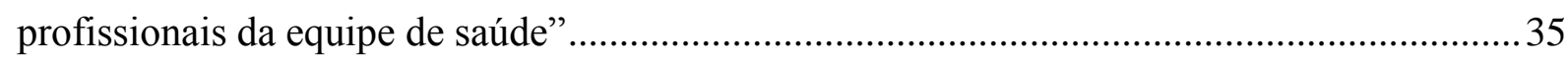

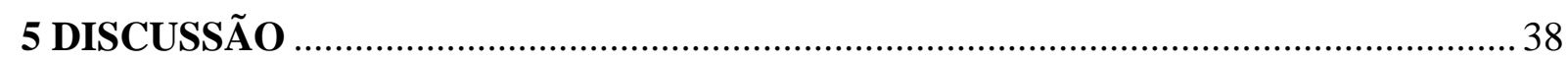

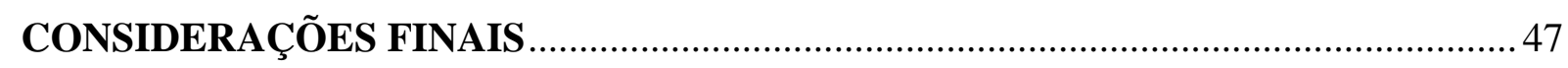

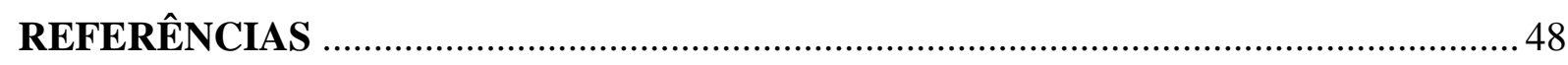

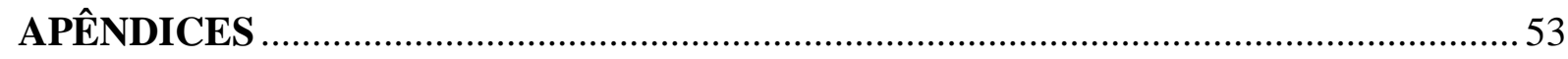

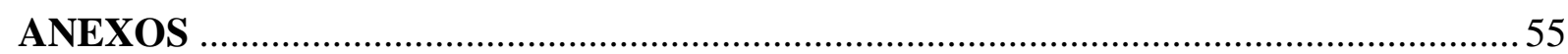




\section{INTRODUÇÃO}

No Brasil, a estruturação do Sistema Único de Saúde (SUS), alicerçado pelos princípios de universalização, descentralização, integralidade e participação social, trouxe à tona a necessidade de buscar saberes e práticas que contribuíssem para a efetividade desde novo modo de atenção. A Atenção Primária à Saúde (APS), porta de entrada no SUS, preconiza ações de promoção à saúde que produzam impactos nos determinantes e condicionantes de saúde das coletividades ao mesmo tempo em que respeitam a autonomia do indivíduo (BRASIL, 2017). O conceito de saúde passa a ser ampliado e não dirigido apenas para o tratamento das doenças, mas contemplando os determinantes sociais envolvidos no processo de saúde-doença da população. Nesse contexto, a APS se revela um campo fértil para o desenvolvimento e incorporação de novas estratégias para a reconstrução da atenção à saúde no país (RIBEIRO, 2007).

A Estratégia Saúde da Família (ESF) é a proposta para alcançar os objetivos preconizados pelo SUS e tem como finalidade integrar ações de promoção e prevenção de saúde, além da assistência individual como elementos diferenciadores para a construção deste modelo, que direciona seu foco para além do individuo, incluindo a família e comunidade em suas ações. Uma característica importante deste modelo é a atuação da equipe de saúde da família, apoiada em um trabalho inter e multidisciplinar, com uma definição de competências e corresponsabilidade entre seus membros (CHIESA; FRACOLLI, 2010). Suas atividades são direcionadas às práticas de cuidado ofertadas de modo democrático e participativo, através do trabalho em equipe e dirigidas às populações de territórios definidos (BRASIL, 2017). Essa proposta de atendimento implica a participação ativa dos pacientes e seus familiares em ações cuidadoras e processos de tomada de decisões (BARRY; EDGMAN-LEVITAN, 2012)

$\mathrm{Na}$ ESF a formação de vínculo entre a comunidade e as equipes de saúde representa um passo crítico que pode ser facilitado por profissionais qualificados em habilidades de comunicação (STEWART, 2010). O aprimoramento dessas habilidades pelos membros das equipes de saúde é fundamental para prover o cuidado qualificado que respeite às preferências individuais das pessoas, assegurando que os pacientes tenham participação ativa nas decisões que envolvam sua saúde (BARRY; EDGMAN-LEVITAN, 2012). Nesse contexto, a comunicação se coloca como elemento essencial para a promoção da saúde, pois permite a troca de informações entre os profissionais, às pessoas e a comunidade.

Ao longo dos últimos 30 anos, pesquisas que abordam a comunicação profissionalpaciente evidenciaram o papel essencial que esta desempenha na qualidade do cuidado na área 
da saúde, permitindo o fornecimento maior de suporte ao paciente, melhoria na satisfação e nos resultados em saúde (GROSSEMAN et al., 2014). No entanto, apesar da crescente valorização da comunicação nas relações profissionais na área da saúde, ainda não há concordância sobre o que seria uma comunicação profissional-paciente adequada (GILLIS et al., 2014; COMERT et al., 2016)

Por definição, a comunicação é um processo social que envolve a troca de informações entre duas ou mais pessoas por meio de símbolos e regras de linguagem. A comunicação em saúde abrange a utilização de técnicas para informar e orientar as pessoas nas tomadas de decisões a nível individual e coletivo, no sentido da promoção a saúde. Profissionais de saúde que utilizam técnicas adequadas de comunicação estão mais aptos a criar e manter uma relação terapêutica e ética com os pacientes, a utilizar a escuta ativa para obter as informações pertinentes, a prover orientações e informações adequadas compartilhando as decisões, e a se comunicar de forma respeitosa com outros membros da equipe de saúde. A qualidade da comunicação durante o atendimento em saúde depende, portanto do desenvolvimento de habilidades como a empatia, cordialidade e do uso da linguagem não verbal, tonalidade da voz, entre outras. O uso adequado da comunicação cria e sustenta a relação profissional-paciente (GROSSEMAN et al., 2014; LAMPERT, 2014; LIBERALI et al., 2018).

O processo de comunicação apresenta três componentes básicos: o verbal, o não verbal e o para verbal (RANJAN et al., 2015). O componente verbal se refere ao conteúdo das mensagens e inclui a seleção de palavras apropriadas. O componente não verbal inclui a linguagem corporal, postura, gesticulação, expressões faciais e espaço físico entre entrevistador e entrevistado. O componente para verbal inclui entonação, textura e volume da voz (RANJAN et al., 2015). Embora o componente verbal seja frequentemente o foco maior da atenção dos profissionais, este responde por apenas $10 \%$ para a qualidade da mensagem recebida pelo paciente, ficando os outros $90 \%$ atribuídos aos componentes não verbais e para verbal. Para assegurar a comunicação efetiva, o componente verbal deve incluir informações sobre a natureza, a evolução e o prognóstico das condições de saúde, além das opções de tratamento, custos e benefícios dos procedimentos. Apesar de ser frequentemente relegado à segundo plano, o componente não verbal da entrevista repercute em importantes desfechos, como o grau de satisfação e a aderências dos pacientes ao plano de cuidados (ROTER et al., 2006).

Kurtz (2002) descreve cinco princípios da comunicação efetiva: 
i) assegurar a interação e não apenas a transmissão da informação com objetivo de estabelecer um entendimento mútuo na relação profissional-paciente, disponibilizando espaço para fazer e responder perguntas, fornecer informações e esclarecimentos, a fim de obter acurácia e eficiência da comunicação;

ii) reduzir incertezas desnecessárias que comprometem a atenção e interferem na eficácia da comunicação, uma vez que a comunicação eficaz assegura o esclarecimento;

iii) requerer planejamento e pensamento em termos de resultados, pois a efetividade da comunicação será determinada pelos resultados que o profissional deseja atingir;

iv) demonstrar dinamismo, considerando-se que o que é apropriado para uma determinada situação pode ser inadequado para outra. Sendo assim, é necessário que o profissional esteja atento ao paciente. Alcançar este dinamismo requer flexibilidade, responsabilidade e envolvimento;

v) seguir o modelo de comunicação em espiral ao invés de um modelo linear para obter um entendimento fidedigno do paciente. Ao colher as informações em forma de espiral, o profissional conduz a conversa de forma que a comunicação evolua gradualmente, movendo-se, cada vez mais, para um nível superior de compreensão, sendo a repetição, a reiteração e o feedback elementos essenciais neste processo.

Portanto, as habilidades de comunicação são consideradas imprescindíveis à interação profissional-paciente e fundamentais para a prática efetiva do cuidado. $\mathrm{Na}$ formação de profissionais de saúde, sua capacitação se mostra essencial, seja nos processos de promoção, prevenção ou reabilitação (DOHMS et al., 2013; LAMPERT, 2014).

No cenário da ESF a assistência à saúde demanda, dos profissionais, um modo diferenciado de estar a serviço do usuário. Os desafios do trabalho no território para a compreensão das necessidades psicológicas, socioeconômicas e de saúde das famílias, exigem dos profissionais competências e sensibilidade para lidar com as vicissitudes contidas neste novo universo (GAÍVA; SIQUEIRA, 2011)

Destarte, a visita domiciliar (VD) apresenta-se como um espaço adequado para iniciar o trabalho com indivíduos, família e comunidade, pois facilita conhecer simultaneamente as práticas assistenciais e as dinâmicas familiares. A VD pode ser realizada de duas formas. A primeira é denominada visita domiciliar "Fim", com objetivos específicos de atuação na atenção domiciliar terapêutica e visita a pacientes acamados. A segunda é a visita domiciliar "Meio", na qual se realiza a busca ativa pela demanda reprimida, promoção e prevenção mediante educação em saúde de maneira individualizada. Estas duas modalidades de visitas são processos dinâmicos e complementares que permitem a abordagem das 
necessidades de saúde da população assistida e a organização do serviço (COELHO; SAVASSI, 2004).

O domicílio, neste sentido, funciona como uma unidade de saúde fora dos muros das instituições formadoras de recursos humanos em saúde, distante do conforto, do espaço e dos recursos materiais, sendo necessária a adequação das intervenções terapêuticas (MARIN et al., 2011). Além do mais, representa um grande espaço interativo para a comunicação do diagnóstico e para a negociação do cuidado (GAGO; LOPES, 2012).

Uma vez que a VD é realizada por diversos profissionais, o conhecimento da sua dinâmica pela ótica dos membros da equipe de saúde permite propor e reordenar ações para ampliar o potencial de intervenção desses profissionais, bem como organizar suas práticas para responder às necessidades das famílias no seu lócus de vida. Este conhecimento aprofundado sobre uma determinada realidade pode ser obtido a partir da vivência do pesquisador no ambiente onde esta realidade se insere.

A comunicação no contexto das visitas pode ser compreendida e analisada através da metodologia qualitativa, que possibilita desvelar, de forma independente, os processos sociais que não estão abertos ou receptivos a esta modalidade de investigação (POPE; MAYS, 2009). O método qualitativo preocupa-se com um nível de realidade que não pode ser quantificado, trabalhando com o universo de significados, motivos, aspirações, crenças, valores e atitudes que, por sua vez, correspondem a um espaço mais profundo das relações, dos processos e dos fenômenos que não podem ser reduzidos à operacionalização de variáveis (MINAYO, 2001).

Neste sentido, o objeto de estudo é o próprio homem e suas relações, e o conhecimento passa a ser construído no relacionamento dialético e na interação dinâmica entre o pesquisador e seu objeto, havendo nesta relação um vínculo indissociável ente o mundo objetivo e subjetivo dos sujeitos. Os dados são construídos em campo, com a participação do pesquisador e dos participantes, sendo esta uma condição sine qua non para a pesquisa (TURATO, 2005, itálico do autor). O foco da atenção não está na replicabilidade dos resultados, mas sim nas configurações singulares, isto é, nas ações e relações sociais travadas por sujeitos e grupos em um determinado momento de suas histórias, as quais jamais poderão ser repetidas em sua integralidade (TURATO, 2005; NOGUEIRA-MARTINS; BÓGUS, 2004).

No setting da saúde, a utilização de métodos qualitativos de investigação é essencial para conhecer as significações dos diversos fenômenos relacionados ao processo saúdedoença e para a melhor compreensão dos sentimentos, ideias e comportamentos dos pacientes, de seus familiares e dos profissionais membros das equipes de saúde (TURATO, 2005, itálico 
do autor). Diferentes estudos permitem a investigação por meio da experiência vivenciada entre os quais destaque-se a pesquisa etnográfica. A etnografia é a descrição densa de um conjunto de entendimentos e de um conhecimento específico que os depoentes fazem de sua própria cultura. Tem como princípio abrir-se para o conhecimento do senso comum, em uma visão de perto e de dentro, permitindo decifrar os códigos que dão sentindo a maneira de pensar e agir (ANGROSINO, 2009). Na pesquisa etnográfica, a coleta de informações e percepções pode ser realizada através de métodos como a observação participante (OP) e as entrevistas individuais semiestruturadas (ANGROSINO, 2009).

A OP consiste na inserção e interação do pesquisador no grupo pesquisado. Imerso no contexto dos sujeitos, partilhando o seu cotidiano, o observador procura compreender e descrever o contexto social a partir da vivência dos observados, identificando as relações de grupo, regras, conflitos e tensões existentes. Não há instrumentos específicos para a coleta, sendo o pesquisador livre para compreender o universo em que está inserido, permitido uma visão em profundidade da realidade estudada (QUEIROZ et al., 2007).

A OP é constituída, sistematicamente, por três etapas. A primeira delas é a aproximação do pesquisador no grupo social estudado. Há nesta fase alguns entraves, tal como desconfiança e resistência do grupo pesquisado. Nesse momento, é importante reduzir a distância entre o pesquisador e os participantes, para que eles se sintam pertencentes e membros protagonistas da pesquisa e não meros objetos de estudo, uma vez que a interação social faz parte da condição da pesquisa. A segunda etapa caracteriza-se pela busca do pesquisador pela compreensão da realidade a qual está inserido. Esta construção é conjunta com o grupo de estudo e pode ser realizada a partir de entrevistas não diretivas com pessoas que possam ajudar na compreensão desta realidade. Os dados coletados devem ser registrados no diário de campo, evitando a perda de informações sobre as observações realizadas. Todos esses instrumentos são fundamentais na coleta e interpretação das informações e estão em constante interação com a produção dos resultados. Após a coleta passa-se para a terceira etapa. Esta ultima, compreende a sistematização e organização das informações para posteriormente serem analisadas (QUEIROZ et al., 2007).

Apesar da crescente tendência em adotar a OP em pesquisas em saúde, o seu uso tem se restringido a ambientes hospitalares, havendo poucos estudos conduzidos em saúde da comunidade. Tal fato pode ser atribuído aos desafios que os pesquisadores encontram ao trabalhar nesse contexto. Alguns autores recomendam que mais estudos sejam conduzidos em saúde da comunidade e que os pesquisadores estejam preparados para lidar com as diversidades encontradas (ZHAO; JI, 2014). 
As entrevistas individuais constituem uma estratégia complementar a OP para o processo investigativo em pesquisas qualitativas. $\mathrm{Na}$ entrevista semiestruturada, o entrevistador pré-estabelece as questões que serão dirigidas aos participantes em uma determinada ordem sequencial. Este modelo de entrevista permite que o participante expresse suas percepções, ideias ou sentimentos com suas próprias palavras, estabelecendo um diálogo interpessoal entre o entrevistador e o sujeito da pesquisa (MINAYO, 2001)

No percurso para compreender a comunicação no contexto das visitas domiciliares, a teoria de Habermas $(1989 ; 1990)$ em relação ao agir comunicativo auxiliou-nos a refletir sobre relevância da ética comunicativa no cuidado em saúde. $O$ autor define a ação comunicativa como a linguagem orientada ao entendimento. Nestas interações, os planos dos participantes são integrados pelo consenso alcançado durante a fala, obtendo acordos que dependem de assentimento racionalmente motivado (racionalidade comunicativa). Este acordo não pode ser imposto por uma das partes ou ser adquirido por meio de manipulações, uma vez que os planos de ação são definidos cooperativamente. Habermas considera que o agir comunicativo se estabelece quando:

[...] os atores tratam de harmonizar internamente seus planos de ação e de só prosseguir em suas metas sob condição de um acordo existente; a comunicação está formulada de tal maneira que seus atos são voltados para o entendimento mútuo, vinculando os planos de ação aos diferentes participantes e dirigindo as ações aos objetivos numa conexão interativa (HABERMAS, 1989, p. 165).

Para o autor, nas ações orientadas ao entendimento, os participantes da interação estão dispostos a atingir seus objetivos levando em consideração a validade dos atos de fala. Inseridos neste contexto, assumem, ao mesmo tempo o papel de falantes e ouvintes, que falam e ouvem, através de processos de entendimento (HABERMAS, 1989, itálico nosso).

Desta maneira, sempre que um interlocutor se manifesta através da fala, levanta-se dúvidas sobre suas pretensões de validade, que incluem veracidade, correção normativa, legalidade e sinceridade, e que devem ser reconhecidas pelo ouvinte. Esse contexto obriga o falante a fundamentar racionalmente a sua fala. $\mathrm{O}$ ouvinte, em contrapartida, pode ou não aceitar a oferta recebida. Entretanto, ao aceitar o ato de fala com o seu "sim", funda-se um acordo entre os participantes. A partir desse acordo, tanto o falante quanto o ouvinte assumem compromissos que serão relevantes para as interações posteriores.

Ofertas de atos de fala somente podem, é verdade, desenvolver um efeito coordenador das ações porque a força cogente de uma ação de fala, compreensível para o ouvinte e aceita por ele, se difunde também para as consequências relevantes da ação. [...] Quem aceita uma ordem, sente-se obrigado a executá-la; quem faz uma promessa, sente-se no dever de 
cumprir, caso seja necessário; quem aceita uma asserção acredita nela e comporta-se de acordo com ela (HABERMAS, 1990, p. 72).

Dito de outro modo, o ouvinte deve reconhecer as pretensões de fala do proponente e o acordo produzido em processos de entendimento deve levar em conta as convicções comuns a todos os atores, não contendo nenhum tipo de coerção que induza ou obrigue os participantes a adotar este ou aquele tipo de conduta (RIVERA; ARTMANN, 2010).

Contudo, nem toda interação mediada linguisticamente representa um exemplo de ação orientada ao entendimento e em muitas ocasiões passa a ser orientada ao êxito ou sucesso individual de uma das partes. Nesse tipo de interação, definida por Habermas como "agir estratégico", a comunicação é direcionada para atingir objetivos individuais. Tanto as ações orientadas ao entendimento (agir comunicativo) quanto aquelas orientadas a uma finalidade individual (agir estratégico), são intercambiáveis, podendo ser utilizadas alternadamente com o mesmo propósito, sem que o resultado final seja prejudicado (HABERMAS, 1989; MELLO,1999)

O agir estratégico contempla dois tipos de ação: a ação estratégica, mais voltada ao indivíduo em seu contexto social e a ação ou racionalidade instrumental, mais voltada ao ambiente não social ou técnico-científico, onde obtêm-se o êxito através de regras de escolha racional e do saber analítico. Segundo Habermas, a ação instrumental é centrada nas tarefas técnicas de controle ou de apropriação da natureza e dos estados das coisas.

[...] a ação instrumental está inserida em uma situação não social, enquanto a ação estratégica localiza- se em uma situação social (que é tratada segundo uma perspectiva formal-utilitária). O êxito vem determinado, no caso da ação instrumental, pela realização de um estado de coisas desejadas, e, no caso da ação estratégica, pelo grau de influência sobre as decisões de um oponente, observando-se regras de escolha racional (e um saber analítico). As ações instrumentais podem estar associadas a interações sociais. As ações estratégicas representam, elas mesmas, ações sociais (RIVERA, 1995, p. 24).

"O saber correlato a essa racionalidade é um saber empírico sobre os melhores meios técnicos, pautado pela objetividade e pela padronização" presente na sociedade moderna (Rivera, 1995, p. 24).

Quanto aos mecanismos de coordenação da ação, no agir comunicativo, a força consensual é dada pelo entendimento linguístico enquanto no agir estratégico depende da influência dos atores uns sobre os outros e sobre a situação da ação. Sob a ótica dos participantes, os dois mecanismos excluem-se mutuamente, visto que ações de fala não podem ter dupla intenção, ou seja, ou são destinadas ao acordo ou ao êxito individual.

Considerando as formas de interação da sociedade moderna, Habermas identifica duas formas de integrações possíveis: a integração social, baseada no agir comunicativo 
(racionalidade comunicativa); e a integração sistêmica, baseada no agir estratégico (racionalidade instrumental). $\mathrm{O}$ autor acredita que a base da racionalidade moderna é instrumental, ou seja, tem como finalidade o conhecimento, a intervenção e a normatização numa síntese de conhecer para dominar (DESLANDES; MITRE, 2009).

Nesse contexto, a Teoria do Agir Comunicativo (TAG) aponta um novo caminho para as sociedades modernas onde a comunicação intersubjetiva é orientada ao entendimento, com a intenção de propor soluções racionais, porém, ancoradas e fundamentadas em uma razão ética e dialógica, para construir e produzir novas relações sociais. A nossa identidade com Habermas tem como ponto de partida esta compreensão, transpondo-a para as relações estabelecidas entre profissionais de saúde e usuários no âmbito da visita domiciliar.

Estabelecidos esses conceitos iniciais, partimos para a investigação sobre a percepção dos profissionais e usuários em relação à atuação, ao trabalho da equipe de saúde da família e à comunicação no contexto das visitas domiciliares através da observação participante e de entrevistas semiestruturadas. Como referencial teórico utilizamos a TAC, buscando o entendimento acerca das interações estabelecidas entre profissionais e usuários no contexto da visita domiciliar. 


\section{OBJETIVOS}

- Investigar a percepção dos profissionais de saúde e dos usuários em relação a sua atuação e ao trabalho da equipe de saúde da família no contexto das VD;

- Verificar a percepção dos profissionais de saúde e dos usuários sobre a comunicação que se estabelece no contexto das VD. 


\section{MÉTODO}

Este estudo teve como cenário a ESF e foi desenvolvido em seis Núcleos Saúde da Família (NSF), localizados no Distrito Oeste da cidade de Ribeirão Preto, interior do estado de São Paulo.

O projeto foi aprovado pelo Comitê de Ética do Centro Saúde Escola da Faculdade de Medicina de Ribeirão Perto/USP, sob o número CAAE 58059016.3.0000.5414, atendendo a todos os requisitos exigidos pela Resolução 196/96 do Conselho Nacional de Saúde e fomentado pela Coordenação de Aperfeiçoamento de Pessoal de Nível Superior (CAPES).

A participação dos sujeitos da pesquisa foi voluntária, mediante convite concordância em participar do estudo através da assinatura do Termo de Consentimento Livre e Esclarecido (TCLE). Os participantes receberam informações em linguagem acessível sobre os objetivos da pesquisa e procedimentos, incluindo a gravação das entrevistas, esclarecimentos sobre os métodos utilizados, liberdade de recusa ou de retirar seu consentimento a qualquer momento e garantia de sigilo sobre suas identidades durante e após o término da mesma.

Foram recrutados profissionais da saúde que realizavam rotineiramente visitas domiciliarias e usuários que as recebiam. Dentre os profissionais de saúde, foram incluídos os médicos, os enfermeiros e os agentes comunitários de saúde (ACS). Para os moradores das áreas adscritas aos NSF foram incluídos os usuários do serviço de saúde maiores de 18 anos, com capacidade para responder as questões da entrevista e que recebessem visita domiciliar regularmente. Foram considerados inelegíveis os profissionais não integrantes a equipe fixa do NSF ou que estivessem ausentes durante o período da coleta, e os usuários e familiares que não estivessem cadastrados ao Núcleo.

Antes do início da coleta dos dados, foi realizado um estudo piloto em um dos NSF, com o objetivo de vivenciar a observação participante e validar o instrumento de coleta. Essa etapa permitiu aprimorar a estrutura do diário de campo, bem como os roteiros da entrevista semiestruturada. Os dados obtidos no estudo piloto não foram utilizados na pesquisa.

A coleta de dados foi realizada mediante seleção intencional, ou seja, por conveniência, e foram coletados no período de setembro de 2016 a abril de 2017, por meio de inserção no campo, observação participante (OP) e realização das entrevistas semiestruturadas. As observações da pesquisadora foram registradas no diário de campo e as entrevistas gravadas e posteriormente transcritas. Em consonância com o método selecionado, optou-se pela amostragem teórica, considerando a variabilidade e qualidade dos 
depoimentos dos sujeitos entrevistados, sendo a coleta de dados interrompida no momento que se verificasse a saturação, onde novas entrevistas não mais acrescentassem novos dados à pesquisa. A amostra final foi constituída por 19 profissionais de saúde e 29 usuários.

Foram utilizados dois roteiros para a coleta de depoimentos, sendo um direcionado aos usuários e outro aos profissionais de saúde, que procuravam compreender suas percepções sobre a comunicação nas VD. O roteiro dos usuários investigava as percepções a partir de três questões básicas: 1) percepção em receber a visita domiciliar; 2) conversa com o profissional durante a visita; e 3) qualidade da visita. O roteiro dos profissionais de saúde foi norteado por quatro questões: 1) percepção em realizar a visita domiciliar; 2) conversa com o usuário durante a visita; 3 ) dificuldades; 4) percepção sobre a visita dos demais profissionais da equipe. As entrevistas com os participantes foram realizadas após as visitas domiciliares, em horários pactuados e em ambientes privativos. Os profissionais de saúde foram entrevistados nas unidades de saúde e os usuários em seus domicílios.

Após transcritas, as entrevistas foram submetidas à exploração e análise, juntamente com os relatos do diário de campo. Para manter o anonimato dos participantes, estes foram apresentados mediante os códigos P, C, M e E, significando, (P) usuários; (A) agente comunitário de saúde; (M) médico e (E) enfermeiras, seguidos por um número dado a cada entrevista.

A análise foi realizada a partir dos dados coletados e permitiu identificar contrastes e similaridades, gerando reflexões e hipóteses norteadoras. Como técnica utilizou-se a Análise de Conteúdo Temático-Categorial, a qual permite através de uma descrição objetiva e sistemática do conteúdo manifesto das entrevistas, produzir inferências replicáveis e aplicáveis, partindo dos dados em direção ao seu contexto (OLIVEIRA, 2008).

A técnica de análise de conteúdo foi realizada de acordo com aquela definida por Bardin (2016), que pressupõe que os dados coletados sejam submetidos às seguintes etapas: a) pré-análise; b) exploração do material; e c) tratamento dos resultados, inferência e interpretação (OLIVEIRA, 2008; BARDIN, 2016).

A primeira etapa, pré-análise, consistiu na fase de organização propriamente dita, sendo um período preparatório para a análise. Fizeram parte deste primeiro processo a escolha dos documentos a serem submetidos à análise; a preparação e edição do material; a leitura flutuante; a formulação das hipóteses e objetivos e a elaboração e escolha de indicadores para fundamentar a interpretação final.

A segunda etapa, exploração do material, consistiu essencialmente em operações de codificação e construção de categorias. A codificação correspondeu ao processo de 
transformação sistemática dos dados brutos do texto, agregando-os em unidades de registro (UR), unidades de contexto (UC) e categorização. Na operação de classificação dos elementos participantes de um conjunto, iniciou-se pela diferenciação e posteriormente realizou-se o reagrupamento.

As UR são unidades de significação codificadas, das quais fez-se a segmentação do conteúdo para a análise. Escolheu-se como tipo de unidade de registro a temática, ou seja, a partir de temas que formaram núcleos de sentido para a comunicação. Em seguida, as UR foram codificadas em UC, para que a dimensão do contexto nos auxiliasse ainda mais na compreensão do conteúdo. Através do processo de categorização foi possível classificar as unidades em categorias empíricas, agrupando-as de acordo com as suas similaridades (OLIVEIRA, 2008).

$\mathrm{Na}$ terceira etapa, o tratamento dos dados iniciou-se pela condensação e destaque das informações obtidas. Os resultados aqui obtidos constituíram as bases para as inferências e interpretações em relação aos objetivos previstos, sendo possível também reconstruir o discurso, compreendendo o processo de comunicação entre profissionais de saúde e usuários no contexto das visitas domiciliares. Nas análises inferenciais e interpretativas foram estabelecidas relações entre os dados obtidos e o referencial teórico. Esta etapa também se configurou em momento de análise crítica e reflexiva e intuição da análise reflexiva em relação aos resultados obtidos. 


\section{RESULTADOS}

\subsection{CARACTERIZAÇÃO DOS SUJEITOS ENTREVISTADOS}

Foram entrevistados 48 participantes, destes, 29 usuários, 10 agentes comunitários de saúde, quatro enfermeiros e cinco médicos. No total, 38 sujeitos eram do sexo feminino $(79,1 \%)$ e os demais, 10 sujeitos, do sexo masculino $(20,9 \%)$.

Dentre os usuários, as idades variaram de 18 a 81 anos, 28 usuários utilizavam exclusivamente o SUS $(96,5 \%)$ e somente um usuário $(3,5 \%)$ utilizava o SUS e plano de saúde privado. Dentre os entrevistados, $26(89,6 \%)$ eram do sexo feminino, 20 (69\%) eram pacientes e $9(31 \%)$ eram cuidadores de pacientes atendidos.

Dentre os ACS, cinco (50\%) eram do sexo feminino e todos tinham recebido curso de formação para ACS. O tempo de atuação na unidade variou de 2 a 11 anos. Somente dois dos entrevistados residiam na mesma área em que atuavam profissionalmente.

Todos os médicos e enfermeiras possuíam formação em Medicina da Família.

\subsection{CATEGORIAS E SUBCATEGORIAS}

A partir da análise etnográfica do conteúdo da OP e das entrevistas semiestruturadas, duas categorias temáticas foram identificadas: "Atuação profissional no contexto das visitas domiciliares" e "O processo de comunicação nas visitas domiciliares".

A seguir, serão apresentados os resultados para cada categoria e suas respectivas subcategorias.

\subsubsection{Categoria 1 "Atuação profissional no contexto das visitas domiciliares"}

Esta categoria relacionou-se aos aspectos gerais da atuação profissional no contexto das visitas domiciliárias e desta categoria, emergiram duas subcategorias: "A VD como espaço de interação entre a equipe de saúde e a comunidade" e "Particularidades na atuação profissional nas VD".

4.2.1.1 Subcategoria “A VD como espaço de interação entre a equipe de saúde e a comunidade" 
A primeira dimensão desta subcategoria manifesta os significados atribuídos à prática da VD, considerando-a como um espaço que proporciona maior interação entre a equipe de saúde e a população. Para os sujeitos desse estudo, as visitas rotineiras dos profissionais de saúde criam com os usuários e suas famílias, vínculos de confiança e afeto que influenciam na relação que os mesmos têm com a equipe de saúde. Nas falas emergiram expressões que traduzem sentimentos positivos e favoráveis à natureza desta ação, tais como: gratidão, felicidade, assistência e cuidado.

As visitas são consideradas importantes pelos usuários que as recebem e são valorizadas pelo acolhimento, a oferta de serviço e a atuação dos profissionais e da equipe. Mencionaram sentimentos de gratidão, bem-estar, atenção e promoção de cuidado, direcionados a eles e seus familiares, como exposto nos depoimentos:

\footnotetext{
"Eu sinto muito assim, lisonjeado! Porque eu acho que é um trabalho importante deles" (P1).

“[...] Esse Núcleo é uma benção aqui! É muito bom! Só agradecer que tem isso aí pra gente e elogiar, porque é uma equipe muito boa!" (P5).

"[...] me sinto bem. Porque pelo menos tem uma pessoa pra me ajudar né? Então é muito bom, ter eles pra ajudar. Tem muita gente por aí que não tem assistência. Então eu acho muito importante" (P3).

"[...] como se fosse uma amiga que a gente recebe, você entende? Que a gente gosta, que a gente quer bem" (P4).
}

Quanto à percepção dos profissionais, estes também enaltecem a assistência e prestação de cuidado a comunidade como a principal potencialidade da VD, seguida do "acesso à saúde", ampliação do acesso aos serviços oferecidos aos usuários e o desenvolvimento de ações de "promoção e prevenção" nas dimensões biopsicossociais:

“[...] normalmente a minha intenção é procurar ajudar ao máximo as pessoas. Tento identificar os pontos que eles têm de necessidade de ajuda [e] o que eu posso ajudar. Eu tento passar o máximo que eu posso pra família, pra tentar ajuda-la. Essa é minha forma de ver a visita: tentar identificar o que eu posso ajudá-los" (A4).

"Eu acho que eu posso, em cada visita, ajudar de alguma forma. Cuidar mais da saúde, tanto físico quanto psicologicamente falando. E a parte social!" (A10).

"Eu me sinto [quando realizo as visitas domiciliares] realmente na minha função de profissional [de saúde, por realizar ações de] promoção $e$ prevenção de saúde. $[\mathrm{O}]$ que é proposto pela Saúde da Família" (E2) 


\begin{abstract}
"As visitas dentro do cuidado com a saúde na Saúde da Família, na Atenção Básica, elas acabam sendo uma ação que a gente [profissional da saúde] faz, e que aumenta o acesso das pessoas [e] a nossa capacidade de prestar atendimento" (M3)

"[...] Acho que a visita é uma ferramenta muito importante, de troca de conhecimento, de cuidado [e] de acesso à saúde. [Acesso] mesmo aqueles que não têm nenhuma dificuldade física, mas psicológica [ou/e] social" (M1)
\end{abstract}

A partir dessas percepções, o aspecto valorizado pelos entrevistados é a VD como meio facilitador da aproximação do serviço com as necessidades dos usuários e famílias atendidas, possibilitando o melhor acesso da população. No domicílio é possível vislumbrar a realidade na qual estão inseridas as pessoas e abordar aspectos mais subjetivos das relações interpessoais construídas no contexto familiar: sujeito-família, sujeito-ambiente e sujeitoprofissional de saúde. Tais aspectos, comparados aos atendimentos no consultório proporciona "um novo olhar" e "outro contato", conforme demonstrado nos relatos:

“[...] [quando o usuário] vem aqui, na Unidade, a gente vai ver ele, só ele! Quando a gente [profissional de saúde] faz uma visita, você vê a família, o contexto social, você vê tudo. Então acaba colhendo mais informações realizando visita domiciliar do que na própria consulta, [quando é atendido] só aqui na Unidade” (E4)

"[...] conhecer mesmo, de entender melhor [...] aquele mundo que ele [o usuário] vive. Pra ter empatia, pra poder entender como o outro vive. Respeitar, saber até onde você pode ir!" (E2)

"Você está vendo ela [a usuária], as demandas dela, o que ela tem de problema. Quando você está no contexto da casa, você entra mais na vida da pessoa, você vê o contexto que ela está inserida, você vê a família, você vê o tipo da casa, consegue perceber várias coisas. Às vezes, coisas que não são relatadas na consulta, quando você faz uma visita, você vê, você observa" (M2)

\title{
4.2.1.2 Subcategoria "Particularidades na atuação profissional nas VD"
}

Para os entrevistados nesse estudo, a VD assume significado específico associado às particularidades de cada atuação profissional. Nos discursos é possível observar as diferenças de significado atribuído também no que concerne à finalidade da visita e ao tipo de assistência prestada.

Nos relatos dos agentes, a VD é vista como sua principal forma de trabalho, parte da sua "rotina" e de sua função de "profissionais de saúde" inseridos na APS. O contato com os 
usuários nos domicílios tem como principal objetivo a "coleta de dados", descritos como "observar e levar" informações para o conhecimento dos demais profissionais da equipe, como apresentado nos discursos:

\footnotetext{
"Quando realizo a VD é sempre na busca de informação: se está tudo bem ou, se a gente já vem sabendo de um problema [que está passando], pra saber se tá melhorando, ou se 'tá' indo, né?! [...] Eu acho que eu consigo tirar o que precisa de informação. É onde a gente traz informação para o Núcleo do que está acontecendo" (A6)

"[...] porque o objetivo nosso [refere-se ao trabalho dos ACS] é estar acompanhando [os usuários], né!? Então, quanto mais informações eu conseguir colher e trazer e registrar melhor" (A5)
}

É no território que o trabalho desses profissionais ganha maior centralidade e notoriedade frente aos demais integrantes da equipe, descritos como o "link entre a população e a Unidade Saúde da Família (USF)”. A partir do que ouvem dos usuários e do seu conhecimento local, os ACS contribuem no planejamento das ações que serão realizadas pela equipe, como pontuou o médico de família: "eles que trazem a demanda, muitas vezes a demanda que a gente não estava vendo" (M5).

Os ACS possuem um vínculo importante com as microáreas onde atuam. Durante a OP pode-se observar que entre uma visita e outra, eles foram abordados por moradores que solicitavam informações acerca dos serviços, dos atendimentos na Unidade e do funcionamento da rede. Além disso, durante o trajeto, os usuários demonstravam carinho por esses trabalhadores, os convidando para passarem em suas casas, tomarem um café e conversarem com seus familiares. Os agentes são descritos como pessoas próximas por quem cultivam amizades, vínculos.

Entretanto, algumas condutas adotadas pelos ACS são claramente identificadas como fiscalizadoras. Em seus discursos os usuários declararam receber advertências sobre suas ausências nas consultas e exames, a falta de adesão ao tratamento e o uso incorreto ou irregular dos medicamentos. Os relatos a seguir reforçam estas situações:

"Mas ele [o ACS] fica em cima, sabe? Ele é desse povo que não abandona. Quando ele pensa que gente esqueceu do Núcleo ele vem aqui." (P19)

“Ah, ele [o ACS] pergunta da saúde da pessoa, qual o remédio que a pessoa está tomando, se o remédio está em ordem, se eu estou indo fazer os exames, perguntam tudo!" (P18). 
Os discursos dos usuários revelaram também que esses se sentiam mais à vontade para relatar suas insatisfações com relação ao serviço e a outros profissionais para os ACS. As queixas estavam relacionadas à dificuldade de agendamento de consultas, insatisfação com o atendimento recebido, dificuldade de solicitar encaminhamentos para outras especialidades e com a sensação de pouco tempo dispensada para realização das consultas. Tais percepções não foram acessíveis nas visitas realizadas pelos médicos e enfermeiras.

Conjuntamente, observa-se que os usuários se sentem mais seguros e confortáveis em revelar suas insatisfações quando estão em suas residências, em relação ao que acontece quando são atendidos na Unidade, embora ainda haja certo receio em falar sobre os aspectos negativos do serviço.

\footnotetext{
"Ai, a gente se sente assim bem! [refere-se às visitas recebidas pelo ACS]. Um pouco mais aliviada das coisas daquele Núcleo! Das coisas [de quando] a gente vai lá e não consegue marcar consulta. Isso chateia!" (P9)

"Falei que eu preciso marcar consulta e não consigo. É só isso!" (P10)
}

Entretanto, embora exista certo grau de insatisfação dos usuários com o serviço, estas percepções não demonstraram estar associadas diretamente à figura e ao trabalho do agentes. Pelo contrário, os usuários demonstraram satisfação quanto à atuação destes trabalhadores, os quais foram reconhecidos pelo seu acolhimento, vínculo e ajuda na resolução dos problemas, como demonstrado no relato do usuário:

"Capaz dele [o ACS] até ajeitar para eu marcar essa consulta. Ah, capaz dele até ajeitar pra mim! Tá entendendo? Ele é muito bacana [chamou o ACS no diminutivo]" (P10).

A respeito de suas atuações nas VD, existem diferenças quanto aos protocolos, condutas que norteiam o trabalho, logística, frequência de visitas, prioridades e temas que são abordados. Observamos que os critérios de organização e planos das visitas são elaborados e estabelecidos pelos próprios profissionais, não havendo padronização para este trabalho. Os resultados destas condutas são retratados nas falas dos usuários, os quais demonstraram falta de periodicidade e a expectativa pelas visitas recebidas por esses profissionais, tal como retratado no relato a seguir:

"Quando ela [refere-se a ACS] passa muito tempo sem vir aqui, eu fico [pensando] 'mas cadê ela?'. As vezes ela custa pra vir aqui. Como é ela 
sozinha, né!? Demora um pouco pra fazer visita. Fazia um tempo que ela não vinha aqui. Quando ela passava, [em frente de casa] eu falava "Oi", e ela [perguntava:] "A senhora está boa?" [E eu respondia:] 'Eu tô boa'. Pra que ela vai vim? Eu estou boa né? (risos)" (P1)

Em âmbito diferente das visitas realizadas pelos agentes, a assistência domiciliar prestada pelos médicos e enfermeiras é compreendida pelos usuários como algo que não é habitual. Em seus discursos relataram sentir-se "privilegiados" em recebê-los em suas casas. Receber o médico e a enfermeira produz um prestigio e status a quem a recebe e uma satisfação a mais com o serviço de saúde, uma vez que, comparam esse tipo de atendimento ao oferecido pelo setor privado, como pode destacado nos relatos dos usuários:

\footnotetext{
"Ah eu me sinto privilegiado, né?! [refere-se a visita da enfermeira]. Não só eu, como todos [os moradores do bairro]. Você receber uma visita em casa assim... Antigamente não existia isso dai... É bom pra gente, que nem ela veio aqui, fez curativo, isso me agrada. Me agrada e está fazendo um bom serviço" (P29)

"Privilegiada! [Refere-se à visita do médico]. Fiquei muito feliz! Porque eu não tenho condição [financeira]. Não tô pagando por isso. E eu acho que tenho assistência igual uma pessoa que está pagando convênio particular, talvez até melhor." (P24).
}

A satisfação com essas visitas está relacionada aos procedimentos realizados e ao acesso oferecido, principalmente, àquelas famílias que possuem algum membro com dificuldade de locomoção. As facilidades geradas pela assistência domiciliar fornecida produzem nessas pessoas os sentimentos de gratidão, assistência e cuidado, por parte da equipe de saúde, como vemos na fala de uma das cuidadoras entrevista:

\footnotetext{
"Antes eu tinha que levar [até a unidade de saúde]. Era muito difícil! Mais difícil pra ele [ refere-se ao marido, o qual recebeu a visita] do que pra mim, né?! Muito mais difícil! Então eu não tendo que tirar ele daqui de casa pra mim é uma benção" (P25)
}

Para os médicos e enfermeiras, a visita é vista como um elemento nobre e representa o "diferencial" que singulariza os serviços oferecidos pela ESF e a atuação da equipe, comparado às demais unidades de saúde, conforme expresso nos seguintes depoimentos:

"A visita possibilita você fazer isso [refere-se ao acesso]., principalmente, dentro da Atenção Primária e Saúde da Família. Então é uma maneira de você atuar na saúde tanto no ponto de vista individual quando do coletiva" (M3) 
"Pra mim o diferencial é você fazer uma visita bem-feita! É vocêfazer uma visita domiciliar para aquelas pessoas que realmente precisam. Se não, a gente não é Saúde da Família, a gente ficaria um postinho. Então, acho que a visita domiciliar é um diferencial! [E] a gente tem que focar naquilo que é diferente!" (E2)

Reafirmam também as potencialidades da VD, sobretudo ao proporcionar a ampliação do acesso aos serviços e ações de saúde e o fortalecimento do vínculo e humanização na atenção às famílias. Por outro lado, revelam a percepção de desvalorização quanto a essa prática no processo de avaliação, direcionado a quantidade e não a qualidade do atendimento. Apontam que o trabalho realizado nas visitas não é visível quando são exigidos resultados do NSF, sendo "um tipo de trabalho que não aparece quando são exigidos números".

Nos discursos das enfermeiras a realização da VD é relatada como prática habitual em sua rotina de trabalho. Essas profissionais demonstraram manter contato mais frequente com as famílias nos domicílios em decorrência das atividades que desempenham no território, tais como, troca de curativos, coleta de exames e acompanhamento em condições específicas (puerpério, recém-nascidos, idosos) quando comparado aos médicos.

Para as enfermeiras, no domicílio os limites entre profissional e usuário não são tão bem estabelecidos quanto nas unidades. Para elas, a postura nas VD apresenta-se como uma dualidade, que transita entre a "amizade" e o profissionalismo. Esta relação intimista, atribuída ao vínculo construído nas VD contribui na receptividade e confiança do usuário. Em contrapartida, há o movimento em manter o papel que desempenha no serviço de saúde, agora, com "cautela" e "cuidado" para não romper os laços construídos e mantendo a formalidade e neutralidade nos atendimentos, como vemos nos depoimentos:

"A gente [profissional de saúde/enfermeira] sempre tem que ter cautela no lidar com o outro: não ser tão enfática em tudo que diz; ser mais flexível, como se fosse, vamos dizer, comer pelas beiradas; não ser, talvez, um pouco mais direta em tudo o que você fala. Porque a pessoa [o usuário que recebe a visita] pode interpretar de uma maneira muito ruim e não querer mais que você esteja ali [na residência]" (E4)

"Então, eu acho que você [profissional que faz VD] tem que tomar muito cuidado com aquilo que você fala, com aquilo que você aborda, porque ele [o usuário] não pediu para você estar ali” (E1)

No discurso da maioria dos médicos, existe uma visão positiva em relação a VD. É considerada uma "importante ferramenta de cuidado", a qual possibilita "ter outro contato" 
com o usuário, "conhecer as suas condições de vida”, criar vínculo, e oferecer acesso à saúde:

"é uma forma de ir até eles [os usuários], de oferecer o serviço, de criar um vinculo, de criar alguma possibilidade" (M1)

"Eu acho que demonstra uma necessidade do paciente, um acolhimento da minha parte, um acolhimento do paciente que abriu a casa para outra pessoa. Eu acho que isso demonstra um vinculo né?! Acho que é bom sim" (M4)

Estes profissionais compararam seus desempenhos durante as VD aos atendimentos realizados no consultório, seja expressando semelhanças ou diferenças. Dentre as semelhanças reveladas destacam: "[as VD] são como se fossem consultas"; "a abordagem é bem parecida". E dentre as diferenças, relatam que na VD: "tem outro contato" com o usuário, que é "mais rico", tem-se "outro olhar", "é um tipo de atendimento diferente", como demonstrado em uma das falas:

\footnotetext{
"Normalmente as visitas são como se fossem consultas médicas, só que no domicílio. A gente pergunta de tudo, se a gente identifica alguma coisa que está diferente ou alguma dificuldade do paciente, a gente tenta abordar. Mas é como se fosse uma consulta, claro que com outro olhar, porque você esta dentro da casa do paciente, você esta vendo quais são as situações, a vulnerabilidade, mas é.. você pergunta de tudo né?!" (M5)

"Eu costumo abordar mais ou menos da mesma forma que eu abordo aqui [na unidade]". Mas, às vezes, o ambiente faz a gente conversar outros assuntos, mas a forma de abordagem com relação ao que ele [o usuário] está sentindo, ao dia-a-dia, costuma ser bem semelhante [ao do consultório] (M2)
}

A aproximação com as dinâmicas familiares implica em desafios para os profissionais. As dificuldades vigentes, não envolvem somente o enfrentamento de doenças ou "problemas biológicos", mas também situações relacionadas ao contexto social, cultural e econômico em que vivem as famílias. Nos relatos dos profissionais são expressos sentimentos de tristeza, angústia e desgaste emocional, ao se verem imersos em um contexto em que a medicina tecnológica pouco tem a ofertar-lhes.

"De fato tem situações bem complicadas, que, às vezes, você fica meio que sem saber o que fazer, porque, tem coisas que, às vezes, não são só problemas biológicos ou físicos. Existem problemas sociais, [que] você não tem nem muito o que agir. Não sei! Tem que pedir ajuda à outro profissional, até de outro setor" (M1). 
"E é um tempo, como se diz, é um tempo que parece que não está contabilizado em nossa agenda, sabe? Assim, a gente tem que ter visita, a gente tem que ter grupo, a gente tem que ter reunião. Mas quando a gente faz uma visita e surge tanta coisa, você demora, às vezes, muito mais tempo. E precisa correr atrás de muito mais coisa” (E1)

"[...] algumas vezes, no caso quando você pega uma situação muito triste, muito chata, a gente se sente pesado, porque sabe que não tem o que mudar. Mas quando há a possibilidade de mudar e de ajudar a gente sente até grato." (A4)

"Problemas, né”?! Vários problemas! As vezes numa mesma família, em diferentes famílias. Então eu tenho que saber lidar com quase todos os diferentes problemas, todas as demandas, todas. (A7)

Os médicos e enfermeiras também relataram situações inesperadas ao realizar as visitas, advindas das condições ambientais de "não ter onde ficar", ser um "ambiente diferente", "um lugar desconhecido"; e algumas vezes até inseguro. Tais situações foram relacionadas ao comportamento das famílias e ao ambiente domiciliar e incluem situações como: receber os profissionais na porta da casa e não convidar para entrar, oferecer alimentos, transitar pela casa durante a visita, ou quando a ambiente apresenta condições de risco aos visitadores. Os relatos, a seguir, remetem a essas concepções:

"Eu acho que na visita do domicílio tem muitos processos que nos [refere-se aos profissionais de saúde] colocam em risco. Como por exemplo: um animal bravo, uma arma, ou qualquer outra coisa que possa colocar nossa segurança em risco, isso incomoda. Porque acho que a gente não tem respaldo nenhum se acontecer alguma coisa com a gente no domicílio, você entendeu? Ai a gente vê como a gente fica exposto. Como é uma exposição de quem recebe a visita, mas também pra gente que está em um lugar desconhecido, né?!" (E4)

“[...] às vezes a gente se surpreende com alguma situação atípica, por exemplo, eu já vi rato durante a visita domiciliar. E também tem aquela situação que o paciente fica desconfortável porque não tem aonde a gente sentar" [...] "Que recebe a gente na porta da casa dele, porque na casa dele não tem muito onde ficar, mas daí ele [o usuário] não parece muito desconfortável. (pausa). É um atendimento bem diferente" (M2, negrito nosso).

As percepções descritas por médicos e enfermeiras também transparecem o desconforto e constrangimento desses profissionais ao se perceberem atuando em um ambiente alheio às suas atribuições. Esse tipo de assistência desperta nos profissionais sentimentos de "invasão", desconforto e insegurança, como demonstrados nos recortes a seguir: 


\begin{abstract}
"Porque eu acho, que de alguma maneira é uma invasão! A pessoa abre a porta de sua casa, pra você que é estranho entrar. É tão relevante e importante estar dentro, só que de alguma maneira, eu penso que você está entrando em um ambiente diferente pra você"'(E2).

"[...] Você ir até a casa das pessoas, você tem a impressão de que está incomodando, esta invadindo um pouco ali. Mas isso é mais no início. Depois você percebe que não, na maioria das vezes você é bem vindo, as pessoas gostam que você. Enfim, mostra atenção, mostra cuidado, então, normalmente as pessoas gostam (M1).
\end{abstract}

Um dos médicos entrevistados correlaciona os desconfortos experimentados durante a VD às limitações de sua própria formação e a falta conhecimento e prática em realizar essa atividade:

\footnotetext{
"No início já foi, talvez foi um pouco mais difícil. Quando a gente esta começando, né?! A fazer as visitas, talvez você se sente um pouco...menos a vontade. A gente durante, por exemplo...eu fui começar a fazer mais visitas...mais não...visitas, assim, na residência de Medicina de Família. Então, durante a faculdade a gente não tinha. Eu não me lembro de ter tido uma disciplina que você visitava as pessoas e tal" (M1)
}

No que se refere aos significados atribuídos a esses profissionais na assistência domiciliar, percebe-se uma preferência por realizar os atendimentos no consultório e não no domicílio, havendo maior familiaridade "quando o usuário procura o atendimento" nas unidades. Essa observação é apoiada no fato de que a unidade oferece estrutura física e conforto para a realizarem os atendimentos, como revelado por um dos médicos entrevistados:

"Para consultar em si a Unidade é melhor, o paciente deita, pesa, é diferente!" (4M)

\title{
4.2.2 Categoria 2 "O processo de comunicação nas visitas domiciliares"
}

Esta categoria relacionou-se especificamente ao processo de comunicação que permeia as relações no contexto das visitas domiciliárias e dela emergiram duas subcategorias: "A comunicação na relação entre usuários e os profissionais da equipe de saúde da família" e "Barreiras e facilitadores da comunicação durante as VD".

4.2.2.1 Subcategoria "A comunicação na relação entre usuários e os profissionais da equipe de saúde da família". 
Os primeiros achados desta subcategoria compreendem as diferenças no processo de comunicação e interação existentes entre os usuários e diferentes profissionais de saúde, no que se relaciona à categoria profissional (agente comunitário, enfermeira e médico), e ao tipo de visita recebida (visita-meio ou visita-fim).

Nas falas dos usuários, esses relatam sentirem-se à vontade com a presença dos agentes. Suas visitas são valorizadas por proporcionar espaços possíveis para compartilhar questões relacionadas à vida e a "outras coisas que estão se passando com a casa", não estando necessariamente, relacionadas à saúde. Em seus diálogos tratam de questões que transcendem a dimensão biológica do cuidado:

"Tem vezes que ela [a ACS] aborda as coisas sobre a minha vida. E é muito bom”. (P11)

"Como se fosse uma amiga que a gente recebe [refere-se às visitas da ACS]. Você entende? Que a gente gosta, que a gente quer bem." (P4)

Por outro lado, os usuários adquirem um novo olhar relacionado à ascensão "se...então", tal como, as visitas realizadas pelos ACS, médicos e enfermeiras. Esta postura reflete na maneira compulsória com que os usuários se percebem ao relacionar-se com o serviço, tal como: "se eu não aceitar a visita dos ACS, então não serei recebida na unidade de saúde"; ou "se eu não falar que cumpro os atendimentos prescritos pelo médico ou a enfermeira, então eu não receberei mais esta assistência”.

De maneira semelhante, os ACS são descritos pelos demais integrantes da equipe como profissionais que tem maior identificação com os usuários:

"[...] às vezes a figura do médico, da enfermeira inibe o paciente. [E] eles [os usuários] conseguem ser mais realistas, demonstrar mais a realidade deles, conversando com o agente comunitário, tem uma identificação maior!' (M1)

Referindo-se à comunicação com os usuários, os ACS evidenciaram que "cada família, cada pessoa é diferente" e "requer um tipo de abordagem diferente". Relataram adotar estratégias para proporcionar momentos de escuta atenta e preocupação com a forma de transmitir informações aos usuários. Revelaram os seus cuidados para "não ser uma visita muito dirigida"; para oferecer um espaço e abertura para o usuário "falar o que acha importante", "falar mais a vontade" e "desabafar"; e a preocupação em adaptar a linguagem, para um vocabulário "simples" e de fácil entendimento, enfatizando e repetindo 
as informações oferecidas a fim de auxiliar a compreensão, como pode ser percebida nos relatos a seguir:

\begin{abstract}
"Eu opto em deixar o paciente mais a vontade, não sigo tanto aquela cartilha: quanto que tá sua glicemia; quanto que tá sua pressão; quanto que deu isso ou aquilo. Eu foco em deixar a pessoa tranquila pra ela me falar o que ela acha que é importante" (A7).

"Eu procuro ser mais simples possível! As vezes eles [os usuários] acham que é repetitivo, mas eu gosto de repetir, frisar bem. Eu acho até pela clientela que tem uma dificuldade de compreender." (A9)
\end{abstract}

Em outros momentos, ao se apresentarem para a comunidade como representantes do serviço de saúde, atuam de forma objetiva buscando informações focadas na doença e comportamentos que influenciam nas condições de saúde dos usuários como hábitos alimentares, relacionamento familiar, contexto social e econômico, uso de medicamentos, frequências nas consultas e exames.

Em suas falas, os ACS justificam suas estratégias de interações com os pacientes, como uma necessidade que busca atender às demandas da equipe de saúde. Eles enfatizam a importância de algumas informações relativas ao comportamento do usuário considerando o "prescrito" pelo médico ou pela enfermeira ou exigido pelo programa. Eles deixam claro que esse tipo de acompanhamento, embora disponível a todos moradores do território, é prioritário para aqueles que possuem algum tipo de doença crônica, como os hipertensos e diabéticos. Nesse momento, o ACS direciona a comunicação para um objetivo pré-definido e assume um tom fiscalizador, como vemos no depoimento:

\footnotetext{
"É o que o médico precisa saber! Se ele [refere-se ao usuário] tá fazendo uso da medicação, se ele foi fazer os exames, se é fora daqui, se ele foi na consulta agendada, pra saber se ele tá dando continuidade no problema dele. As vezes só de rotina, mas se ele tá fazendo o seguimento correto" (A8)
}

No que se refere às suas próprias visitas, para os médicos e enfermeiras, o processo de comunicação relaciona-se aos objetivos pré-definidos, demandas das famílias e ao tempo disponível para realização da VD. As visitas-fim, ou seja, com o propósito do atendimento a um problema clínico específico, são percebidas como focais e direcionadas a um membro da família, e as visitas-meio, relacionadas ao contexto social, são "abrangentes" e "informais": Esta última também é compreendida por alguns profissionais como uma possível atitude de 
coerção aos usuários com caráter "impositivo" e de "polícia", como demonstra o discurso de uma das enfermeiras:

"[...] eu acho que por mais que você vai com o sentido de orientar, fica um caráter de cobrança. Uma busca ativa é o que mais demanda, então fica muito esse caráter impositivo. Por mais que a gente tenta não levar só nesse sentido, fica! E a família não tem vínculo com a Unidade” (E3)

De acordo com os médicos e enfermeiras, a abordagem específica de condições clínicas previamente conhecidas e os procedimentos técnicos realizados são os principais temas abordados durante as visitas:

"[...] a gente [durante as visitas] aborda sempre a questão daquilo que você foi fazer especificamente. Se você foi pra fazer curativo, a gente acaba abordando a questão. Se é hipertenso, diabético, a gente acaba abordando também, mas a gente vai naqueles casos específicos. Se é paciente acamado a gente aborda contexto clinico, se é curativo, se é só curativo e o paciente não tem mais nada, a gente aborda o contexto do curativo. Mas a gente acaba fazendo um pouquinho de tudo, uma consulta clinica e as orientações [necessárias] daquela visita, naquele dia” (E2)

"Depende do assunto que você via tratar. Normalmente se for uma consulta [ou] uma avaliação [é] mais objetiva, né!? Mas, as vezes você quer ir lá para conhecer a família, pra criar vinculo, pra saber algumas coisas além da parte biológica. Tem consultas rápidas que você já vai até aonde você precisa fazer, no tempo que você tem pra fazer. As vezes tem visitas mais longas, mais programado, conversas mais difíceis, dependendo do assunto. A maioria, [é] tranquilo” (M1)

Os discursos das enfermeiras revelam preocupação com a atuação profissional nas VD. Esses aspectos não foram relatados pelos médicos. Essas profissionais manifestaram cuidados em distanciar-se da postura de "detentor de todo do conhecimento" para compreender e aproximar do contexto da família, e adotar estratégias que favoreçam a recepção dos usuários, tal como, flexibilidade nas orientações e cautela quanto ao estilo da abordagem, conforme a expressão de uma enfermeira:

"A gente sempre tem que ter cautela no lidar com o outro, não ser tão enfática em tudo, ser mais flexível, como se fosse, vamos dizer 'comer pelas beiradas' [...] Não ser talvez um pouco mais direta em tudo o que vocêfala, porque a pessoa pode interpretar de uma maneira muito ruim [...] e a pessoa não querer mais que você esteja ali'(E2).

"A gente identifica [a necessidade de realizar uma visita] por algum motivo ou uma necessidade de saúde! E ai vai pra uma visita. Na visita nem sempre aquele motivo que eu estou indo é o motivo que ela [a usuária] reconhece 
como um motivo. Então, eu acho que significar isso dentro do espaço dela é muito mais complexo, muito mais delicado pra fazer sentido. Porque se não, você invade um espaço que tem que ser protegido. A casa de todo mundo precisa ser um espaço protegido. [É] A nossa casa! A gente não quer que qualquer um entre lá e fale tudo o que quer, por [melhor] intenção que tenha, por mais que seja um profissional de saúde, mas não é detentor da verdade, da pura verdade, que vai fazer sentido pra ela" (E1)

4.2.2.2 Subcategoria "Facilitadores e barreiras da comunicação durante as VD: percepção dos profissionais da equipe de saúde”

Os profissionais entrevistados demonstraram suas percepções sobre aspectos facilitadores e restritivos em seus processos de comunicação. De modo geral, todos os aspectos relacionados a facilitadores e barreiras da comunicação foram introduzidos nos discursos, entretanto, se apresentam de forma mais ou menos pontual conforme a atuação estabelecida nas visitas.

Nas falas de todos os profissionais existe a percepção de que a comunicação é permeada por relações interpessoais. Essas relações são dependentes do enquadramento, da categoria profissional, do tipo de relacionamento e do vínculo.

Como facilitadores deste processo os ACS enfatizaram o vínculo e a receptividade; e os demais profissionais destacam, além do vínculo, o agendamento, a flexibilidade e o conhecimento prévio da população do território.

$\mathrm{Na}$ visão dos membros das equipes, o vínculo estabelecido entre profissional-usuário é considerado peça fundamental no processo de comunicação nas VD. Concomitantemente compreendem que a ausência deste elemento representa uma barreira a esse processo. Descrevem que os comportamentos de usuários que "não dão abertura", "não aceitam ajuda" ou "não estão com vontade de receber a visita" constituem os principais empecilhos para a comunicação. Esta situação pode ser percebida nos seguintes relatos:

\footnotetext{
"Ah normalmente eu não costumo ter muita dificuldade [de comunicação], não. Apenas aquelas famílias que tem aquela barreira já própria de não querer conversar muito, não querer dialogar. Essas pessoas eu acabo não conversando, não buscando muita informação porque eu já sei que a pessoa não quer passar" (A4)

"Eu acho que tem pacientes que você tem mais dificuldades então, você fica um pouco menos a vontade. Mas isso também acontece no consultório, que são os pacientes que a sua relação não é tão boa, que o nível de empatia é menor, que você pode ter tido algum tipo de conflito" (M3)
} 
"Às vezes acontece dificuldade assim, de você ir [e] esperar que a conversa vai fluir melhor por parte do paciente, e não ser dessa maneira" (E3)

Outra dificuldade evidenciada está relacionada ao contexto e às condições sociais dos usuários. Atribuem contrariedades ao vivenciar situações complexas e de grande vulnerabilidade social durante as visitas, como: condições ruins de moradia, saneamento, de alimentação, pobreza e violência. Esta perspectiva embora presente em todos os discursos mostrou-se permanente nas falas dos médicos e das enfermeiras. De acordo com eles este cenário desvencilha-se das "questões relacionadas à saúde" e "puramente biológicos ou físicos", exigindo novas estratégias de atuação e interação, com os usuários, intersetorial e multiprofissional, bem como, maior sensibilidade e equilíbrio emocional, como destacado no depoimento:

\footnotetext{
"Acho que tem visitas que são mais dificeis, porque a situação é difícil, a família é complicada, os problemas são graves. Ás vezes, a gente fica até perdido. A solução, às vezes, não depende só de questão de saúde, às vezes são outros setores" (M1)

"Mas eu acho que, a gente acaba vendo muita coisa social. E isso é um desafio! Porque não conseguimos ter governabilidade pra muita coisa. Então, condições ruins de moradia, de saneamento, de alimentação, isso gera um pouco de angustia. Você tem que acionar recursos [e], muitas vezes, precisa sair do campo da saúde, puramente biológico. Você vai para saúde em outros aspectos. E que aí envolver intersetor. E isso é mais complexo" (E1)
}

Embora não haja percepção formal pelos profissionais da existência de dificuldades próprias relacionadas à comunicação e relação interpessoal no contexto da VD, surgem falas que deixam transparecer certo despreparo para lidar com situações que envolvem essa habilidade:

"Tem certas pessoas que quer ouvir até o que você não está preparado para falar, você está entendendo? Ela quer ouvir alguma coisa de mim que, às vezes, eu não posso ajudar" (A7)

"De fato tem situações bem complicadas, que você fica meio sem saber o que fazer. Porque tem coisas que não é só problema biológico ou físico, existem problemas sociais. Você não tem nem muito o que agir. Não sei! Tem que pedir a ajuda de outro profissional, até de outro setor" (M1)

O que é difícil é quando você chega em uma casa e a pessoa não quer te receber. Eu vou lá e aí a pessoa esta com raiva, trata mal. Eu fico morrendo de pena, juro! Eu fico com pena, ou me dá vontade de rir. Às vezes, a pessoa é tão nervosa que eu falo: "nossa que mal humor é esse, Deus me livre que 
eu fique desse jeito'. Sabe assim, eu não pego, 'isso não é pra mim', ' não é comigo', eu penso que [é assim] com todo mundo e eu sou mais um pra essa pessoa'. Mas eu vim [refere-se à visita] aqui pra fazer meu serviço. Eu tô aqui pra fazer, eu vou e faço! Tento desempenhar da melhor forma possível. [E quando] A pessoa não gosta, eu não dou nem bola" (M4)

Aquelas situações [refere-se à comunicação durante as visitas], às vezes, que tem muito problema ou a realidade é muito complicada. Mas porque é uma situação difícil do paciente e não da relação profissional e paciente. Então, acho que difícil não é a melhor palavra que define, mas pode ser aquela consulta que te exige mais do ponto de vista emocional, do ponto de vista de até você ver uma situação e você fica mexido (M3)

"Olha, eu sempre falei isso [refere-que quanto a ser moradora do território]. Desde o começo do programa eles falam que é bom. É bom para o paciente mas, não é bom pra gente, pro profissional, porque você fica invadido o tempo todo. É o tempo todo! Você é procurado, você vai na farmácia, você vai no supermercado, você tá no açougue, tem sempre alguém da área que quer falar alguma coisa. Já fui de estar no shopping e encontrar um paciente e ele continuar falando. Dai sempre tem aquela orientação: corta o paciente! Mas eu tenho a dificuldade de cortar o paciente no local que não é o horário de serviço, porque depois você vai bater na casa dele, e ele vai falar: 'quando eu tava querendo ajuda você nem quis me ouvir'. Então eu tenho um pouco de dificuldade nesse sentido, de cortar o paciente fora do horário de trabalho" (A2)

"Quando tem alguma reclamação, que você tenta explicar, o paciente está insatisfeito é difícil! Porque o paciente não entende ou então não depende só de você. Principalmente, se o paciente vem aqui e é mal atendido na recepção ou no acolhimento ou não gostou de alguma coisa que o médico falou. Ai a gente não tem como orientar a conversar, às vezes, ele tem alguma reclamação muito grande e não ajuda. Se pega alguma impressão ruim do serviço" (A3)

"Dificuldade [refere-se à comunicação] eu falo sempre dessas famílias que 'está tudo bem' [se referindo às famílias que não querem conversar]". Tem [famílias] com doença crônica, com crianças. [E] ele [o usuário] não está com vontade [de falar], não é um dia bom para fazer visita. Isso me deixa angustiada. Eu converso com a enfermeira, sobre essas coisas, e ela [responde]: "às vezes é a abordagem, tenta perguntar isso", eu falo: "é, pode ser". Eu tento até mudar minha abordagem, pra ver se eu consigo, mas tem família que é do "tudo bem" (A10) 


\section{DISCUSSÃO}

A $\mathrm{OP}$ e as entrevistas individuais semiestruturadas proporcionaram valiosas contribuições ao entendimento do processo de comunicação que se estabelece entre profissionais e usuários no contexto das VD. Dadas as suas características, esses métodos de pesquisa etnográfica propiciam uma compreensão em profundidade do tema investigado, em uma oportunidade única que contempla diversos olhares, incluindo o do pesquisador. A inserção do pesquisador no campo permite a este vivenciar as relações que se estabelecem entre os sujeitos e triangular suas percepções aos relatos obtidos nas entrevistas individuais.

De acordo com os resultados desse estudo, vários aspectos positivos no que concerne à VD como a rotina de atendimento, o acolhimento aos usuários, o acesso aos serviços de saúde e o vínculo de confiança que se estabelece entre as famílias e os profissionais da equipe foram ressaltados por todos os entrevistados. Essa percepção vai de encontro ao preconizado pela ESF, que tem no acesso aos cuidados em saúde um dos pilares fundamentais para o fortalecimento do SUS (BRASIL, 2017). A ESF, portanto, requer uma mudança na relação entre os profissionais e a população, resgatando e valorizando conceitos fundamentais como vínculo, humanização, corresponsabilização e respeito às individualidades, reorientando o modelo de cuidado centrado na doença para a atenção centrada na pessoa em busca de melhores resultados em saúde (STARFIELD, 2004).

Para os profissionais de saúde entrevistados, adentrar no espaço das famílias confere um novo significado aos atendimentos e, nessa perspectiva, possibilita a obtenção de informações adicionais sobre a vida dos usuários, suas rotinas e hábitos, suas relações sociais e condições econômicas. Em relação às particularidades da atuação profissional nas VD, as práticas assistenciais nos domicílios possuem significados diferentes para cada membro da equipe considerando a observação de suas próprias atuações. Neste sentindo, a visita amplia a visão das condições reais de vida da família e possibilita a interação em ambientes familiar e social, através do conhecimento do cotidiano, da cultura, dos costumes, das crenças de uma determinada sociedade, o que torna essas vivências enriquecedoras para ambos ( DRULLA et al., 2009; CRUZ; BOURGET, 2010). As ações realizadas no domicílio se destacam como ações direcionadas a promoção de saúde, prevenção de doenças e de reabilitação, visto que o ambiente familiar constitui o cenário onde ocorrem as relações sociais de risco a saúde e de adoecimento dos indivíduos (GAÍVA; SIQUEIRA, 2011).

Nos relatos dos agentes, a VD é vista como sua principal forma de trabalho na equipe de saúde, tendo como objetivo principal a coleta de informações. De acordo Política Nacional 
de Atenção Básica (PNAB), as atribuições dos ACS incluem a integração da equipe de saúde com a população, o trabalho com a adscrição das famílias em território definido, o desenvolvimento de ações educativas, o registro e atualização dos cadastros nos sistemas eletrônicos de informação, a orientação quanto às formas de utilização dos serviços de saúde, além de atividades orientadas a promoção, prevenção e vigilância em saúde (BRASIL, 2017).

Para os demais membros da equipe, os ACS são vistos como o principal elo entre a população e o NSF. Durante a OP pode-se observar o acesso informal aos ACS pelos moradores locais. Atuando como mediadores sociais, os ACS por um lado apresentam para a equipe as necessidades da população, e por outro asseguram o vínculo e a identidade cultural das famílias sob sua responsabilidade em relação às ações ofertadas pelo serviço (DRULLA et al., 2009; LIMA et al., 2010; FILGUEIRAS; SILVA, 2011; GAÍVA; SIQUEIRA, 2011).

Algumas condutas adotadas pelos ACS são claramente identificadas como fiscalizadoras pelos usuários entrevistados nesse estudo. Estudos apontam que a atuação curativista do ACS está relacionada aos resultados exigidos pelas equipes de saúde, tais como: o uso correto dos medicamentos, a adesão ao tratamento prescrito; ou "estar em dia com suas consultas e exames" (LIMA et al., 2010). Essa prática também é considerada como um traço das visitas higienistas realizadas no início do século XX cuja intenção era de fiscalizar as atitudes da população quanto aos seus cuidados com a saúde (FILGUEIRAS; SILVA, 2011). Sendo responsáveis pela troca de informações entre os usuários e a USF, é compreensível a percepção do papel "fiscalizador" dos ACS por parte de alguns usuários. Embora exista certo grau de insatisfação dos usuários com o serviço, este não se relaciona diretamente ao trabalho dos ACS. Sabe-se que a dinâmica de trabalho dentro das USF não necessariamente se equivale ao trabalho dos ACS no território (FERRAZ; AERTS, 2005).

No tocante a organização do trabalho dos ACS, percebeu-se uma heterogeneidade de atuação não havendo padronização em relação à logística e frequência. Segundo o PNAB, os ACS devem visitar mensalmente as famílias pelas quais são responsáveis em suas microáreas ou território de adscrição (BRASIL, 2017). Entretanto, de acordo com Ferraz e Aerts (2005), a maioria dos ACS considera impossível realizar as visitas em todas as casas mensalmente, priorizando as famílias que mais necessitam de acompanhamento. A definição de critérios para a organização das VD pelos próprios ACS, também é problematizada no estudo de Cunha e Sá (2013). Os autores referem que a falta de padronização produz diferenças no acesso da população dentro do mesmo território. Dependendo do perfil do ACS que faz cobertura em determinada área, apenas alguns grupos terão acesso aos serviços oferecidos pela unidade de saúde. A criação de vínculos entre os ACS e o usuário, ao mesmo tempo que 
é desejável, pode influenciar a quantidade de tempo despendido entre as VD, resultando em uma dedicação maior a determinadas famílias em detrimento de outras. O desenvolvimento do trabalho de forma isolada, sem se apoiar em uma coordenação geral, pode resultar em iniquidades e ameaçar a garantia da integralidade e do acesso equitativo.

Neste estudo, as visitas realizadas pelos médicos e enfermeiras estão associadas a certo grau de prestígio por parte dos usuários. De acordo com o PNAB (BRASIL, 2017), as VD realizadas por esses profissionais são destinadas prioritariamente aos usuários que possuem problemas de saúde controlados e com dificuldade ou impossibilidade física de se locomoverem até a unidade de saúde. Tais aspectos corroboram com os achados da pesquisa de Gaíva e Siqueira (2011) onde se percebe uma maior dedicação por parte desses profissionais às famílias que apresentem membros doente.

A partir dos discursos dos médicos e das enfermeiras, podemos inferir sentimentos de dualidade em relação à VD que é percebida ao mesmo tempo como algo que favorece a construção de vínculo, mas que também apresenta um caráter invasivo, inseguro e desafiador. Em seus discursos, os entrevistados tecem comparações entre o atendimento na VD e no consultório, ressaltando o caráter de informalidade do primeiro. Nesse contexto, a unidade de saúde surge como um mediador do trabalho e das relações interpessoais, proporcionando maior segurança aos profissionais. Essa percepção é corroborada no estudo de Borges e D’Oliveira (2011), que retrata o "clima intimista" da VD em contraposição ao "clima mais técnico" do consultório, onde o profissional médico representa a autoridade. Para as autoras, no consultório também predomina a impessoalidade, atributo de uma medicina mais tecnológica. Dessa forma, ao adentrar no ambiente domiciliar, o profissional depara-se com o fato de não pertencer ao contexto em que atua e se vê desafiado a adequar as suas intervenções para incluir a participação da família na prática dos cuidados em saúde (GAGO; LOPES, 2012).

Neste sentido, embora a VD seja identificada na ESF como a atuação da equipe fora dos muros das instituições formais de saúde, em seus relatos, os profissionais ainda desejam carregar consigo todas as formalidades contidas no ambiente institucional. Constatou-se, portanto, que o atendimento dos médicos e enfermeiras durante a VD tende a reproduzir aquele realizado no consultório. Tais achados corroboram com o estudo de Cruz e Bourget (2010), que se referem às práticas dos profissionais durante as VD como centradas na doença evidenciando a adoção de um modelo curativista em contraposição ao modelo proposto pela ESF. Devido à abordagem centrada na doença, aspectos como a autonomia e corresponsabilização tornam-se secundários no cuidado em saúde. A possibilidade de 
mudança dessa lógica de atendimento no contexto domiciliar exige dos profissionais maior autenticidade e habilidade para lidar com as diversidades encontradas neste espaço. Estudos demonstram que a presença de um profissional de saúde aberto ao processo de escuta e conversa na unidade de saúde, repercute direta e positivamente na satisfação do usuário com o cuidado prestado na APS (GOMIDE et al., 2018). Sendo assim, surge a necessidade de uma formação que incorpore no processo de aprendizagem oportunidades para exercitar o diálogo de saberes e a negociação entre os diferentes atores na busca por melhores desfechos nos cuidados em saúde.

Em relação ao processo de comunicação nas VD existem diferenças relacionadas a categoria profissional e ao tipo de visita recebida. A partir da OP e das entrevistas com usuários, pode-se verificar que existe uma facilidade maior na comunicação entre estes e os ACS quando comparados aos demais membros da equipe. No território onde atuam, os ACS constroem vínculos e identidade com a população assistida, o que se traduz em seu pertencimento ao mesmo universo dos usuários e da comunidade local. Estes aspectos favorecem a compreensão dos conflitos, das necessidades e das condições de saúde dos usuários, das famílias e da comunidade (CARDOSO; NASCIMENTO, 2010). Tal identificação entre ACS e usuários foi também reconhecida nos discursos dos demais integrantes da equipe. O convívio com a comunidade, captando suas necessidades, permite que os ACS transmitam à equipe o território vivo, isto é, os aspectos culturais e intersubjetivos das famílias, a maneira com que elas interpretam, explicam e se reconhecem em seus cuidados com a saúde.

Para os ACS, a comunicação com os usuários deve ser ajustada ao perfil de cada indivíduo ou família visitada evitando-se padrões muito rígidos de conduta. Estes profissionais se consideram responsáveis por ações de vinculação e de conhecimento dos modos e hábitos da população. Suas atuações demonstram maior aproximação às condições de vida, representações culturais, papéis sociais e processos de socialização contidos na comunidade. Este tipo de interação requer desses profissionais escuta, estabelecimento de vínculo, laços de confiança, abertura para o diálogo e conhecimento das diferenças; isto é, um agir orientado ao entendimento, que possibilite dar voz aos usuários considerando todo o contexto onde vivem (HABERMAS, 1990).

Assim, ao adentrarem no espaço íntimo das moradias, os ACS escutam os desabados, os conflitos familiares, as histórias de vida espontaneamente contadas pelos usuários e dividem suas próprias histórias e experiências, proporcionando um espaço de trocas de vivências subjetivas aproximando-os dos contextos e das necessidades de saúde dessa 
população. No entanto, em outros momentos, ao apresentarem-se para a comunidade como representantes do serviço de saúde, devolvem aos moradores respostas centradas no saber técnico biomédico. Ao exigir a adesão da população aos projetos e propósitos institucionais, os profissionais dão mais importância à eficiência da ação do que ao processo. Os ACS justificam essas condutas como uma necessidade para alcançar os objetivos do programa e/ou atender às demandas da equipe de saúde. Têm-se nesse momento, um deslocamento do agir orientado ao entendimento para o agir orientado para o sucesso. Essa conduta não prioriza o diálogo de saberes entre instituição e população como é preconizado pela APS e não promove ações reflexivas em torno das questões que afetam diretamente o sujeito e o mundo em que ele vive (OLIVEIRA, 2011).

Para os médicos e enfermeiras, o processo de comunicação durante as VD relacionase aos objetivos pré-definidos, demandas das famílias e ao tempo disponível para realização das mesmas. A maioria não menciona preocupação com uma abordagem comunicacional que favoreça o compartilhamento de decisões e parece não reconhecer o usuário como sujeito que tem desejos, conhecimentos prévios, crenças, cultura e processos de cuidado. Nos discursos, o processo de comunicação é prioritariamente orientado para obtenção de sucesso em suas atuações na VD. Esses resultados são corroborados por outros estudos que consideram que nos processos de trabalho em saúde predomina a razão técnico-científica, que sustenta a ação voltada para o sucesso no restabelecimento biológico (SILVA; PEDUZZI, 2011; JUSTO et $a l ., 2015)$. No entanto, consideram ser necessário buscar a interação dialógica para incluir a subjetividade presente na interação profissional-usuário (SILVA; PEDUZZI, 2011).

Quando analisamos a comunicação entre profissionais e usuários na VD utilizando como referencial a Teoria do Agir Comunicativo de Habermas, observamos que todos os profissionais de saúde entrevistados assumem posturas que evidenciam em seus processos de trabalho o uso tanto da razão instrumental quanto da razão comunicativa, com o predomínio da primeira nas atividades desempenhadas nas VD (HABERMAS, 1990; DESLANDES; MITRE, 2009)

Para Habermas (1989), as comunicações estabelecidas entre as pessoas se baseiam em seus esforços de entendimento mútuo a partir de suas referências culturais (mundo objetivo), da sociedade em que estão inseridas (mundo social) e de suas próprias vivências (mundo subjetivo). A interação entre esses três mundos leva aqueles que se comunicam à compreensão do que o autor chama de "Mundo da Vida", o contexto no qual os sujeitos estão inseridos e no qual constroem seus processos de entendimento. Nessa concepção, o diálogo, só existe a partir do reconhecimento das singularidades e de reflexões sobre o mundo no qual 
se está inserido. No "Mundo da Vida", a comunicação precisa ser pautada na garantia do direito de cada interlocutor em emitir seus pensamentos, opiniões e decisões. Nessa concepção, o próprio ato de interagir é a solução para os problemas que surgem quando pessoas diferentes precisam elaborar um plano de ação conjunto. No entanto, esta interação pode ser direcionada ao agir comunicativo, quando as pessoas que interagem buscam o consenso ou ao agir estratégico, quando buscam o êxito individual (HABERMAS, 1989; MELO, 1999; GUTIERREZ; ALMEIDA, 2013).

No agir comunicativo a linguagem busca o entendimento, indo além de simplesmente compreender o que é dito, mas implicando na aceitação do que é dito e de suas consequências, contribuindo para a corresponsabilização e autonomia dos envolvidos (CESTARI, 2002). Dessa forma, quando o profissional de saúde estabelece com o usuário uma relação baseada no agir comunicativo não ocorrerá a hegemonia de quem domina o conhecimento sobre o leigo. Nesse tipo de interação são reconhecidas as limitações do paciente e existe a busca por um equilíbrio, para que não prevaleça somente a voz do detentor do maior saber técnico. Para que impere a racionalidade comunicativa, a relação profissionalusuário deve ser construída com base em uma ética profissional de mútuo respeito e confiança (DESLANDES; MITRE, 2009).

Por outro lado, se durante o diálogo são desconsideradas as vivências subjetivas do processo saúde-doença e os aspectos inerentes ao mundo da vida, não poderemos dizer que essa interação busca o entendimento. Nesse tipo de interação, os profissionais lançam mão da razão instrumental para alcançar seus objetivos e passam a agir estrategicamente. Nessa racionalidade instrumental, a linguagem funciona apenas como veículo de informação, não havendo preocupação com o consenso, mas apenas com o resultado final (ARAÚJO, 2004). Deste modo, quando os profissionais pronunciam assertivas acerca do que é certo ou errado, ou do que deve ou não ser feito e prescindem os determinantes sociais do processo de interação e comunicação, podemos dizer que não apresentam uma visão abrangente sobre o universo do usuário no contexto da VD.

A crítica à razão instrumental técnico-científica recai no uso de tecnologias comunicativas tradicionalmente comandadas por ideologias dominantes que geram a exclusão social do saber não-hegemônico (OLIVEIRA, 2011). Nessa perspectiva, pode-se usar da influência, persuasão, oferta de gratificação e ameaças para se alcançar o objetivo final. Essa forma de atuação não alcança todo o leque de necessidades de saúde dos usuários quando consideramos a saúde um direito orientado à integralidade e à equidade. Para alcançar esse objetivo é preciso reconhecer a necessidade de outras ferramentas de trabalho além do arsenal 
técnico-científico, pois os profissionais que atuam no SUS devem estar preparados para ouvir o usuário, entender sua inserção em seu contexto social e, a partir daí atender às demandas e necessidades desta pessoa de forma integral (SILVA; PEDUZZI, 2011).

Todos os profissionais entrevistados consideraram o vínculo com o usuário a peça fundamental no processo de comunicação, sendo a sua presença vista como um facilitador e a sua ausência uma grande barreira. O contexto da visita, a infraestrutura deficitária dos domicílios e as condições socioeconômicas precárias dos usuários também foram apontados como barreiras à comunicação. Nos discursos dos profissionais, todas as dificuldades de comunicação apontadas na relação profissional-usuário foram atribuídas aos usuários. De acordo com Araújo (2004) no campo das políticas públicas e na saúde coletiva, a comunicação é utilizada apenas como um veículo de informação e não contempla os processos sociais implícitos nessas interações. Considerando o predomínio da razão instrumental sobre a comunicativa nos processos de trabalho, os profissionais podem incorrer no risco de não incluir a perspectiva dos pacientes nos diálogos estabelecidos durante as VD e imputarem todo o "insucesso" da comunicação a dificuldades relativas ao usuário e ao contexto no qual está inserido, tal qual foi verificado na fala dos entrevistados neste estudo.

Embora não destacado como um aspecto facilitador pelos sujeitos desse estudo, sinalizamos a importância das reuniões de equipe, discussão do contexto das famílias e as atividades de educação continuada realizadas nos NSF. Oferecer um espaço aberto para o diálogo entre os membros da equipe apresenta-se como uma oportunidade de desenvolver ações comunicativas entre seus integrantes, possibilitando a construção de consensos compartilhados. Nesse sentindo, Justo et al. (2015), consideram que o trabalho em equipe pode oferecer uma resposta comunicativa às dificuldades de interação e consenso. Apesar de não ser um processo de alcance fácil, o diálogo aberto às diversas solicitações pode redefinir responsabilidades e competências de seus integrantes, especialmente nas situações mais preocupantes que requerem respostas mais imediatas e dependem do apoio de todos os componentes.

Nenhum dos entrevistados relatou dificuldades pessoais para se comunicar. Todavia, durante a OP e as entrevistas, observou-se que em situações que requeriam uma abordagem comunicacional mais técnica e/ou cuidadosa, houve uma dificuldade manifestada por vários profissionais em relação a "saber o que e como falar". Tais aspectos foram observados no cadastro de novas famílias pelos ACS na abordagem de temas considerados tabus sociais (sexualidade, raça e etnia) e durante a atuação de médicos e enfermeiras diante de condições socioeconômicas precárias ou cenas constrangedoras. Diante dessas situações, a maioria dos 
profissionais optou por ignorar o acontecido e não abordar o tema com o usuário. Para Stelet et al. (2017), a comunicação dos profissionais de saúde com os pacientes deve ir além do uso (ou não-uso) de certas frases ou de determinado estilo de conversa, mas consistir em uma busca, por parte do profissional de uma maneira de interagir com o outro em meio à sua realidade, respeitando seus sentimentos e saberes. Por isso, considera-se que o profissional da saúde deve ser o responsável por coordenar a ação utilizando conscientemente a razão comunicativa, em busca do consenso. No entanto, não pode ser exigido desses profissionais que atuem em uma lógica para a qual não foram formados ou que tenham desempenho satisfatório em competências para as quais não receberam treinamento específico.

Consideramos que lidar com as singularidades das famílias, excedendo os aspectos biológicos, compreendendo sua subjetividade e suas formas de cuidado é uma tarefa que exige dos profissionais novas competências. Como apontado por um dos médicos entrevistados nesse estudo, a falta de treinamento para realizar a VD é um fator importante de desconforto e angustia para o profissional. De maneira geral, o processo de formação dos profissionais de saúde se faz a partir de suas interações no ambiente da prática clínica, sendo a interação profissional-paciente a principal estratégia educacional utilizada. Os cenários de prática profissional, incluindo os domicílios, são ambientes propícios para o aprendizado da racionalidade comunicativa, por meio da construção de relações dialógicas entre docentes, estudantes e pacientes (CESTARI, 2002; ROMANHOLI; CYRINO, 2012). Nesse sentido, Ramanholi e Cyrino (2012), apontam que a VD pedagógica (aquela utilizada como estratégia educacional), permite ao profissional em formação vivenciar a realidade social das famílias, desenvolver habilidades de comunicação e de relação interpessoal para lidar com os desafios presentes nessa interação. Diante disso, consideramos o espaço da VD como um ambiente oportuno para o treinamento da racionalidade comunicativa na relação profissional-usuário incorporando novas estratégias de ensino-aprendizagem no processo de formação profissional tanto na graduação como na residência.

No Brasil, a grande maioria das instituições de ensino ainda se apoia na razão instrumental técnico-científica que utiliza a comunicação basicamente para transmitir informações. Os profissionais formados nessa lógica tendem a levar esse modelo para as relações construídas no mundo do trabalho (CESTARI, 2002). Somente a revisão da racionalidade presente no ambiente universitário suscitará uma reflexão crítica sobre a realidade e assim, poderá transformá-la. Ensinar na área da saúde é uma atividade complexa que envolve aspectos técnico-científicos, éticos e atitudinais. O desafio colocado para os educadores é qualificar os futuros profissionais para serem capazes de se relacionar de forma 
efetiva com as pessoas sob seus cuidados, reconhecendo-as como detentoras de direitos, autonomia e repertório cultural próprios. Nesse sentido, a Teoria do Agir Comunicativo de Habermas nos aponta um novo caminho, que permite integrar diferentes dimensões tanto na formação profissional quanto na melhoria do cuidado em saúde ofertado às pessoas. 


\section{CONSIDERAÇÕES FINAIS}

A comunicação que se estabelece na VD não pode ser capturada pelos métodos convencionais de pesquisa porque ocorre em um universo subjetivo e dinâmico. O uso da pesquisa etnográfica através da OP e de entrevistas semiestruturadas possibilita a triangulação de dados e a melhor compreensão desse processo.

As VD são consideradas importantes pelos usuários que as recebem, as quais são valorizadas pelo acolhimento, pela oferta de serviços e pela atuação dos profissionais da equipe.

Os ACS são valorizados pela comunidade local e o seu papel é reconhecido na fiscalização, orientação e facilitação do acesso ao serviço de saúde. Em contrapartida, os usuários sentem-se mais à vontade para se comunicar com estes profissionais, comparado aos demais. Em suas visitas os usuários podem compartilhar assuntos do seu cotidiano que não estejam relacionados somente às questões de saúde.

Existe uma preocupação por parte de médicos e enfermeiras quanto às incertezas e inseguranças relacionadas ao ambiente da VD. Algumas enfermeiras salientam o fato de que as VD representam uma invasão no espaço intimista das famílias e também em relação a prepotência do saber por parte dos profissionais. Propõem flexibilidade nas orientações e cautela quanto ao estilo da abordagem. Por parte dos médicos existe uma preferência pelas consultas realizadas em Unidades de Saúde à qual estão mais familiarizados.

O enfoque Habermasiano da ação comunicativa representa um referencial apropriado para o entendimento da comunicação no contexto das VD. Na interação entre profissionais e usuários na VD, o agir estratégico e a racionalidade instrumental são predominantes em relação ao agir comunicativo. Estes aspectos podem apresentar como consequências dificuldades na construção de vínculos, na aquisição de autonomia e compreensão do contexto sócio cultural no qual o usuário está inserido.

Dificuldades na comunicação durante as VD são frequentemente atribuídas aos usuários e ao seu contexto social pelos profissionais de saúde, que não reconhecem claramente suas limitações em relação a essas habilidades. A comunicação efetiva nas VD requer treinamento direcionado às habilidades de comunicação na formação dos profissionais de saúde. 


\section{REFERÊNCIAS}

ANGROSINO, M. Etnografia e observação participante. Porto Alegre: Artmed, 2009.

ARAÚJO, I. S. D. Mercado simbólico: um modelo de comunicação para políticas públicas. Interface, Botucatu, v. 8, p. 165-178, 2004.

BARDIN, L. Análise de conteúdo. Tradução Luís Antero Reto, Augusto Pinheiro. São Paulo: Edições 70, 2016.

BARRY, M. J.; EDGMAN-LEVITAN, S. Shared decision making - the pinnacle of patientcentered care. New England Journal of Medicine, Salzburg, v. 366, p. 780-781, mar. 2012.

BORGES, R.; D'OLIVEIRA, A. F. P. L. A visita médica domiciliar como espaço para interação e comunicação em Florianópolis, SC. Interface, Botucatu v. 15, p. 461-472, 2011.

BRASIL. Portaria n ${ }^{\circ}$ 2.436, de 21 de setembro de 2017. Aprova a Política Nacional de Atenção Básica, estabelecendo a revisão de diretrizes para a organização da Atenção Básica, no âmbito do Sistema Único de Saúde (SUS). Diário Oficial da União, Brasília, DF, 21 set. 2017. Disponível em: <

http://bvsms.saude.gov.br/bvs/saudelegis/gm/2017/prt2436_22_09_2017.html>. Acesso em: 3 jun.2018.

CARDOSO, A. D. S.; NASCIMENTO, M. C. D. Comunicação no Programa Saúde da Família: o agente de saúde como elo integrador entre a equipe e a comunidade. Ciência \& Saúde Coletiva, Rio de Janeiro, v. 15, p. 1509-1520, jun. 2010.

CESTARI, M. E. Agir comunicativo, educação e conhecimento: uma aproximação ao pensamento de Habermas. Revista Brasileira de Enfermagem, Brasília, v. 55, n. 4, p. 430433, jul./ago. 2002.

CHIESA, A. M.; FRACOLLI, L. A. O trabalho dos agentes comunitários de saúde nas grandes cidades: análise do seu potencial na perspectiva da promoção da saúde. Rev Bras Saúde Família, São Paulo, v. 7, p. 42-49, 2010.

COELHO, F. L. G.; SAVASSI, L. C. M. Aplicação de Escala de Risco Familiar como instrumento de priorização das Visitas Domiciliares. Revista Brasileira de Medicina de Família e Comunidade, Rio de Janeiro, v. 1, n. 2, p. 19-26, 2004. 
COMERT, M. et al. Assessing Communication Skills of Medical Students in Objective Structured Clinical Examinations (OSCE)--A Systematic Review of Rating Scales. PLoS One, v. 11, n. 3, mar. 2016.

CRUZ, M. M.; BOURGET, M. M. M. A visita domiciliária na Estratégia de Saúde da Família: conhecendo as percepções das famílias. Saúde e Sociedade, São Paulo, v. 19, p. 605-613, jul./set. 2010.

CUNHA, M. S. D.; SÁ, M. D. C. A visita domiciliar na estratégia de saúde da família: os desafios de se mover no território. Interface, Botucatu, v. 17, p. 61-73, jan./mar. 2013.

DRULLA, A. et al. A visita domiciliar como ferramenta ao cuidado familiar. Cogitare Enfermagem, Curitiba, v. 14, n. 4, 2009.

DESLANDES, S. F.; MITRE, R. M. D. A. Processo comunicativo e humanização em saúde. Interface, Botucatu, v. 13, p. 641-649, 2009.

DOHMS, M.; TESSER, C. D.; GROSSEMAN, S. Potencialidades no ensino-aprendizagem da comunicação médico-paciente em três escolas brasileira, espanhola e holandesa. Revista Brasileira de Educação Médica, Florianópolis, v. 37, p. 311-319, 2013.

FERRAZ, L.; AERTS, D. R. G. D. C. O cotidiano de trabalho do agente comunitário de saúde no PSF em Porto Alegre. Ciência \& Saúde Coletiva, Chapecó, v. 10, n. 2, p. 347-355, 2005.

FILGUEIRAS, A. S.; SILVA, A. L. A. Agente Comunitário de Saúde: um novo ator no cenário da saúde do Brasil. Physis: Revista de Saúde Coletiva, Rio de Janeiro, v. 21, n. 3, p. 899-916, 2011.

GAGO, E. A.; LOPES, M. J. Cuidados domiciliares-interacção do enfermeiro com a pessoa idosa/família. Acta Paulista de Enfermagem, Portugal, v. 25, n. 1, p. 74-80, 2012.

GAÍVA, M. A. M.; SIQUEIRA, V. D. C. A. A prática da visita domiciliária pelos profissionais da estratégia saúde da família. Ciênc Cuid Saúde, v. 10, n. 4, p. 697-704, 2011.

GILLIS, A. E.; MORRIS, M. C.; RIDGWAY, P. F. Communication skills assessment in the final postgraduate years to established practice: a systematic review. Postgraduate Medical Journal, Ireland, dez. 2014. Disponível em: <http://pmj.bmj.com/content/early/2014/12/02/postgradmedj-2014-132772.abstract>. Acesso em 14 ago. 2018. 
GOMIDE, M. F. S. et al. A satisfação do usuário com a atenção primária à saúde: uma análise do acesso e acolhimento. Interface, Botucatu, v. 22, n. 65, 2018.

GROSSEMAN, S. et al. Projeto Ensino de Habilidades de Comunicação na Área da Saúde: uma trajetória inicial. In: ASSOCIAÇÃO BRASILEIRA DE EDUCAÇÃO MÉDICA. Cadernos da ABEM. Rio de Janeiro: Associação Brasileira de Educação Médica, v. 10, 2014. cap. 2. p. 7-12.

GUTIERREZ, Z.G.L.; ALMEIDA, M.A.B. Teoria da ação comunicativa (Habermas): estrutura, fundamentos, e implicações do modelo. Veritas, Porto Alegre, v. 58, n.1, jan./abr.,2013.

HABERMAS, J. Consciência moral e agir comunicativo. Tradução Guido A. de Almeida Rio de Janeiro: TempoBrasileiro, 1989.

Pensamento pós-metafísico: estudos filosóficos. Tradução Flávio Beno Siebeneichler. Rio de Janeiro: Tempo Brasileiro, 1990.

JUSTO, C. M. P.; GOMES, M. H. D. A.; SILVEIRA, C. Limites e imposições dos instrumentos de controle do trabalho de agentes comunitários de saúde da Estratégia Saúde da Família. Saúde e Sociedade, São Paulo, v. 24, n. 2, p. 594-606, 2015.

KURTZ, S. M. Doctor-patient communication: principles and practices. Canadian Journal of Neurological Sciences, Canadá, v. 29, n. S2, p. S23-S29, 2002.

LAMPERT, J. B. Habilidades de Comunicação e Qualidade de Vida/Saúde. In: ASSOCIAÇÃO BRASILEIRA DE EDUCAÇÃO MÉDICA. Cadernos da ABEM, Rio de Janeiro: Associação Brasileira de Educação Médica, v. 10, 2014. cap. 1. p. 3-6.

LIBERALI, R. et al. Communication skills teaching in Brazilian medical schools: What lessons can be learned? Patient Educ Couns, v. 101, n. 8, p. 1496-1499, ago. 2018.

LIMA, A. N. D.; SILVA, L.; BOUSSO, R. S. A visita domiciliária realizada pelo agente comunitário de saúde sob a ótica de adultos e idosos. Saúde e Sociedade, São Paulo, v. 19, n. 4, p. 889-897, 2010.

MARIN, M. J. S. et al. O sentido da visita domiciliária realizada por estudantes de medicina e enfermagem: um estudo qualitativo com usuários de unidades de saúde da família. Ciência \& Saúde Coletiva, Marília, v. 16, n. 11, p. 4357-4365, 2011. 
MELO, E. M. Fundamentos para uma proposta democrática de saúde: a teoria da ação comunicativa de Habermas. Tese (Doutorado) Universidade de São Paulo: Ribeirão Preto, 1999.

MINAYO, M. C. Ciência, técnica e arte: o desafio da pesquisa social. In: social: teoria, método e criatividade. 18. ed. Petrópolis: Vozes, 2001. cap. 1, p. 9-29.

NOGUEIRA-MARTINS, M. C. F.; BÓGUS, C. M. Considerações sobre a metodologia qualitativa como recurso para o estudo das ações de humanização em saúde. Saúde e sociedade, v. 13, n. 3, p. 44-57, set. 2004.

OLIVEIRA, D. C. D. Análise de conteúdo temático-categorial: uma proposta de sistematização. Rev. enferm. UERJ, Rio de Janeiro, v. 16, n. 4, p. 569-576, 2008.

OLIVEIRA, R. N. D. C. O agir comunicativo no contexto das práticas de educação em saúde pública: um estudo à luz da teoria da ação comunicativa de J. Habermas. Serviço Social \& Sociedade, São Paulo, n. 106, p. 267-283, 2011.

POPE, C.; MAYS, N. Pesquisa qualitativa na atenção à saúde. Artmed Editora, 2009. ISBN 8536318570.

QUEIROZ, D. T. et al. Observação participante na pesquisa qualitativa: conceitos e aplicações na área da saúde. Rev. enferm. UERJ, Rio de Janeiro, v. 15, n. 2, p. 276-283, 2007. ISSN 0104-3552.

RANJAN, P.; KUMARI, A.; CHAKRAWARTY, A. How can doctors improve their communication skills? Journal of clinical and diagnostic research: JCDR, v. 9, n. 3, p. JE01, 2015.

RIBEIRO, F. A. Atenção primária (APS) e sistema de saúde no Brasil: uma perspectiva histórica. Dissertação (Mestrado) Universidade de São Paulo: São Paulo, 2007.

RIVERA, F. J. U. Agir comunicativo e planejamento social: uma crítica ao enfoque estratégico. SciELO-Editora FIOCRUZ, 1995. ISBN 8575412485.

RIVERA, F. J. U.; ARTMANN, E. Planejamento e gestão em saúde: histórico e tendências com base numa visão comunicativa. Ciência \& Saúde Coletiva, Rio de Janeiro, v. 15, p. n.2, 2265-2274, 2010. ISSN 1413-8123. 
ROMANHOLI, R. M. Z.; CYRINO, E. G. A visita domiciliar na formação de médicos: da concepção ao desafio do fazer. Interface, Botucatu, v. 16, n. 42, p. 693-705.

ROTER, D. L. et al. The expression of emotion through nonverbal behavior in medical visits. Journal of general internal medicine, v. 21, n. 1, p. 28-34, 2006.

SILVA, J. A. M. D.; PEDUZZI, M. Educação no trabalho na atenção primária à saúde: interfaces entre a educação permanente em saúde e o agir comunicativo. Saúde e Sociedade, São Paulo, v. 20, n. 4. p. 1018-1032, 2011.

STARFIELD, B. Atenção primária: equilíbrio entre necessidades de saúde, serviços e tecnologia. In: Atenção primária: equilíbrio entre necessidades de saúde, serviços e tecnologia. Brasília: UNESCO, Ministério da Saúde, 2004.

STELET, B. P.; CASTIEL, L. D.; MORAES, D. R. D. Anomalisa e o ensino da comunicação clínica na prática médica. Cadernos de Saúde Pública, v. 33, n. 2, p. e00154016, 2017.

STEWART, M. Medicina centrada na pessoa: transformando o método clínico. Tradução Anelise Teixeira Burmeister. Porto Alegre: Artmed, 2010.

TURATO, E. R. Métodos qualitativos e quantitativos na área da saúde: definições, diferenças e seus objetivos de pesquisa. Rev. de Saúde Pública, Campinas, v. 39, n. 3, p. 507-514, 2005.

ZHAO, M.; JI, Y. Challenges of introducing participant observation to community health research. ISRN nursing, v. 2014, 2014. 


\section{APÊNDICES}

APÊNDICE A: Roteiro da entrevista com os usuários

Quando você recebe visitas dos agentes comunitários de saúde em sua casa:

- $\quad$ Com você se sente?

- $\quad$ Como foi a conversa com este profissional durante a visita ?

- $\quad$ Fale-me mais sobre isso...

Quando você recebe visitas da enfermeira em sua casa:

- $\quad$ Com você se sente?

- Como foi a conversa com este profissional durante a visita ?

- $\quad$ Fale-me mais sobre isso...

Quando você recebe visitas do médico em sua casa:

- Com você se sente?

- Como foi a conversa com este profissional durante a visita ?

- $\quad$ Fale-me mais sobre isso... 
APÊNDICE B: Roteiro da entrevista com os profissionais de saúde

Quando você faz visita na casa das famílias:

- $\quad$ Com você se sente?

- $\quad$ Como você conversa com as pessoas?

- Quais dificuldades você encontra?

- Qual a sua opinião em relação visitas realizadas por outros membros da equipe (médico / enfermeira/ agente comunitário de saúde)? 


\section{ANEXOS}

ANEXO A - Termo de Consentimento Livre e Esclarecido Usuários

\section{TERMO DE CONSENTIMENTO LIVRE E ESCLARECIDO: USUÁRIOS}

Título da Pesquisa: "A comunicação no contexto das visitas domiciliares: uma investigação das percepções de profissionais e usuários na estratégia saúde da família" Pesquisadores responsáveis: Marina Dias Lelis, Gustavo Salata Romão Número do CAAE: 58059016.3.0000.5414

Você está sendo convidado a participar como voluntário de uma pesquisa. Este documento, chamado Termo de Consentimento Livre e Esclarecido, visa assegurar seus direitos como participante e é elaborado em duas vias, uma que deverá ficar com você e outra com o pesquisador.

Por favor, leia com atenção e calma, aproveitando para esclarecer suas dúvidas. Se houver perguntas antes ou mesmo depois de assiná-lo, você poderá esclarecê-las com o pesquisador. Se preferir, pode levar este Termo para casa e consultar seus familiares ou outras pessoas antes de decidir participar. Não haverá nenhum tipo de penalização ou prejuízo se você não aceitar participar ou retirar sua autorização em qualquer momento.

\section{Justificativa e objetivos:}

O objetivo deste estudo é investigar como a comunicação e as relações entre as pessoas se processam durante as visitas domiciliares. Durante esse encontro podemos conhecer aspectos importantes da comunicação entre as equipes e as famílias. Por isso, através desse trabalho, pretendemos investigar como a comunicação acontece nas visitas domiciliares sob o olhar dos profissionais das equipes de Saúde da Família e dos usuários e suas famílias. Estas informações serão valiosas para os programas de treinamento de profissionais de saúde.

\section{Procedimentos:}

Participando do estudo você está sendo convidado a:

1. Assinar o presente Termo de Consentimento Livre e Esclarecido (TCLE) redigido em duas vias onde os pesquisadores se comprometem a cumprir todos os preceitos e as normas da Ética em Pesquisa com Seres Humanos conforme Resolução CNS nº466/2012 do Conselho Nacional de Saúde.

2. Permitir que durante um período de três meses (doze semanas) a pesquisadora acompanhe as visitas realizadas pelos profissionais de saúde em sua casa, registrando informações e percepções em seu diário de campo com ênfase na sua forma de comunicar e se relacionar com os profissionais das equipes de saúde da família.

3. Participar de uma entrevista que será realizada posteriormente ao período de observação de suas atividades. Esta etapa visa investigar suas vivências e percepções sobre comunicação e relação interpessoal no contexto das visitas domiciliares. A pesquisadora fará perguntas sobre suas percepções em relação às visitas domiciliares e os aspectos que facilitam e dificultam a comunicação durante este trabalho. Para facilitar e registro das informações, o conteúdo das entrevistas 
será gravado, em dispositivo eletrônico de áudio, para posterior transcrição e análise do conteúdo.

4. Estar ciente de que os profissionais que fazem visita à sua casa também serão entrevistados sobre suas vivências e percepções sobre comunicação e relação interpessoal no contexto das visitas domiciliares.

5. Esta pesquisa requer apenas sua participação em dois momentos diferentes e será realizada em sua casa.

\section{Desconfortos e riscos:}

A sua participação neste estudo não implica em grandes riscos físicos. Do contrário, você poderá se sentir desconfortável, constrangido ou incomodado ao responder as perguntas que a pesquisadora irá lhe fazer. Caso sentir-se deste modo, você poderá interromper a entrevista e retornar em outro momento, quando sentir-se mais confortável, reagendando conforme sua disponibilidade de dia e horário.

\section{Benefícios:}

Os resultados deste estudo serão importantes para nortear estratégias de ensino e aprendizagem em habilidades de comunicação na área da saúde, com benefícios potenciais para os profissionais em formação e a população por eles atendida. Esse estudo, portanto, poderá contribuir para qualificar a atenção à saúde das pessoas.

\section{Acompanhamento e assistência:}

Em participando da pesquisa você será visitado(a) pela pesquisadora que acompanhará as visitas domiciliares realizadas durante o período de estudo e posteriormente será entrevistado(a) pela mesma a respeito de suas percepções e opiniões sobre as visitas domiciliares. A sua participação neste estudo, não implica em qualquer risco para o seu bemestar e saúde.

Através deste documento fica assegurado o seu direito a obter todos os esclarecimentos que considerar necessários. $\mathrm{O}$ método utilizado não representa nenhum tipo de intervenção traumática e nenhum dos procedimentos usados oferece riscos à dignidade do participante. Entretanto, como afirmado antes, se a participação neste estudo lhe causar constrangimento ou desconforto emocional, fique à vontade para encerrar sua participação.

\section{Sigilo e privacidade:}

Você tem a garantia de que sua identidade será mantida em sigilo e nenhuma informação será dada a outras pessoas que não façam parte da equipe de pesquisadores. $\mathrm{O}$ conteúdo do diário de campo e as gravações das entrevistas realizadas pela pesquisadora serão armazenadas de forma sigilosa pelos pesquisadores por um período de cinco anos e depois serão excluídas completamente dos arquivos. Durante o período de armazenamento o conteúdo das mesmas não será divulgado. Na divulgação dos resultados desse estudo, sua identidade não será citada ou revelada.

\section{Ressarcimento e Indenização:}

O participante não terá nenhum tipo de despesa ao participar desta pesquisa, bem como nada será pago por sua participação. Você terá a garantia ao direito à indenização diante de eventuais danos decorrentes da pesquisa.

\section{Contato:}

Em caso de dúvidas sobre a pesquisa, você poderá entrar em contato com os pesquisadores Marina Dias Lelis Monteiro e Gustavo Salata Romão, nos telefones (16) 3602- 
2433 ou (17)9.8192-3431, endereço Av. Bandeirantes, 3900, CEP. 14.049-900 - Ribeirão Preto/SP, e-mail: marina_lelis@ usp.com.br.

Em caso de denúncias ou reclamações sobre sua participação e sobre questões éticas do estudo, você poderá entrar em contato com a secretaria do Comitê de Ética do Centro Saúde Escola, da Faculdade de Medicina de Ribeirão Preto, da Universidade de São Paulo, pelo telefone, (16) 3315-0000, e endereço, Rua Teresina, 690, bairro Sumarezinho.

\section{O Comitê de Ética em Pesquisa (CEP).}

O papel do CEP é avaliar e acompanhar os aspectos éticos de todas as pesquisas envolvendo seres humanos. A Comissão Nacional de Ética em Pesquisa (CONEP), tem por objetivo desenvolver a regulamentação sobre proteção dos seres humanos envolvidos nas pesquisas. Desempenha um papel coordenador da rede de Comitês de Ética em Pesquisa (CEPs) das instituições, além de assumir a função de órgão consultor na área de ética em pesquisas

\section{Consentimento livre e esclarecido:}

Após ter recebido esclarecimentos sobre a natureza da pesquisa, seus objetivos, métodos, benefícios previstos, potenciais riscos e o incômodo que esta possa acarretar, aceito participar e declaro estar recebendo uma via original deste documento assinada pelo pesquisador e por mim, tendo todas as folhas por nós rubricadas:

Nome do (a) participante:

Contato telefônico:

E-mail (opcional)

Data:

\footnotetext{
(Assinatura do participante ou nome e assinatura do seu RESPONSÁVEL LEGAL)
}

\section{Responsabilidade do Pesquisador:}

Asseguro ter cumprido as exigências da resolução 466/2012 CNS/MS e complementares na elaboração do protocolo e na obtenção deste Termo de Consentimento Livre e Esclarecido. Asseguro, também, ter explicado e fornecido uma via deste documento ao participante. Informo que o estudo foi aprovado pelo CEP perante o qual o projeto foi apresentado. Comprometo-me a utilizar o material e os dados obtidos nesta pesquisa exclusivamente para as finalidades previstas neste documento ou conforme o consentimento dado pelo participante.

Data:

(Assinatura do pesquisador) 
ANEXO B - Termo de Consentimento Livre e Esclarecido Profissionais de Saúde

\section{TERMO DE CONSENTIMENTO LIVRE E ESCLARECIDO: PROFISSIONAIS DE SAÚDE}

Título da Pesquisa: "A comunicação no contexto das visitas domiciliares: uma investigação das percepções de profissionais e usuários na estratégia saúde da família" Pesquisadores responsáveis: Marina Dias Lelis, Gustavo Salata Romão Número do CAAE: 58059016.3.0000.5414

Você está sendo convidado a participar como voluntário de uma pesquisa. Este documento, chamado Termo de Consentimento Livre e Esclarecido, visa assegurar seus direitos como participante e é elaborado em duas vias, uma que deverá ficar com você e outra com o pesquisador.

Por favor, leia com atenção e calma, aproveitando para esclarecer suas dúvidas. Se houver perguntas antes ou mesmo depois de assiná-lo, você poderá esclarecê-las com o pesquisador. Se preferir, pode levar este Termo para casa e consultar seus familiares ou outras pessoas antes de decidir participar. Não haverá nenhum tipo de penalização ou prejuízo se você não aceitar participar ou retirar sua autorização em qualquer momento.

\section{Justificativa e objetivos:}

O objetivo deste estudo é investigar como a comunicação e as relações entre as pessoas se processam durante as visitas domiciliares. Durante esse encontro podemos conhecer aspectos importantes da comunicação entre as equipes e as famílias. Por isso, através desse trabalho, pretendemos investigar como a comunicação acontece nas visitas domiciliares sob o olhar dos profissionais das equipes de Saúde da Família e dos usuários e suas famílias. Estas informações serão valiosas para os programas de treinamento de profissionais de saúde.

\section{Procedimentos:}

Participando do estudo você está sendo convidado a:

1. Assinar o presente Termo de Consentimento Livre e Esclarecido (TCLE) redigido em duas vias onde os pesquisadores se comprometem a cumprir todos os preceitos e as normas da Ética em Pesquisa com Seres Humanos conforme Resolução CNS nº66/2012 do Conselho Nacional de Saúde.

2. Permitir que durante um período de três meses (doze semanas) a pesquisadora acompanhe você em sua rotina de visitas domiciliares, registrando informações e percepções em seu diário de campo com ênfase na sua forma de comunicar e se relacionar entre os membros das equipes de saúde e os membros das famílias visitadas.

3. Participar de uma entrevista que será realizada posteriormente ao período de observação de suas atividades. Esta etapa visa investigar suas vivências e percepções sobre comunicação e relação interpessoal no contexto das visitas domiciliares. A pesquisadora fará perguntas sobre suas percepções em relação ao seu papel no contexto das visitas domiciliares e os aspectos que facilitam e dificultam a comunicação durante este trabalho. Para facilitar e registro das informações, o conteúdo das entrevistas será gravado, em dispositivo eletrônico de áudio, para posterior transcrição e análise do conteúdo. 
4. Estar ciente de que os usuários visitados por você durante o período desse estudo também serão entrevistados sobre suas vivências e percepções em relação a comunicação e relação interpessoal no contexto das visitas domiciliares.

5. Esta pesquisa requer apenas sua participação em dois momentos diferentes e será realizada em seu local de trabalho.

\section{Desconfortos e riscos:}

A sua participação neste estudo não implica em grandes riscos físicos. Os pequenos desconfortos se relacionam a possíveis interferências em sua prática de trabalho durante a coleta dos dados. Para minimizar tal inconveniência o acompanhamento às visitas domiciliares será realizado de acordo com sua rotina e a entrevista será previamente agendada, de acordo com a sua disponibilidade.

Durante a entrevista, você poderá se sentir incomodado ou constrangido ao responder as perguntas à pesquisadora. Caso sentir-se deste modo, você poderá interrompê-la e retomar em outro momento quando sentir-se mais confortável, reagendando novamente.

\section{Benefícios:}

Os resultados deste estudo serão importantes para nortear estratégias de ensino e aprendizagem em habilidades de comunicação na área da saúde, com benefícios potenciais para os profissionais em formação e a população por eles atendida. Esse estudo, portanto, poderá contribuir para qualificar a atenção à saúde das pessoas.

\section{Acompanhamento e assistência:}

Em participando da pesquisa você será acompanhado(a) pela pesquisadora nas visitas domiciliares realizadas durante o período de estudo e posteriormente será entrevistado(a) pela mesma a respeito de suas percepções e opiniões sobre as visitas domiciliares. A sua participação neste estudo, não implica em qualquer risco para o seu bem-estar e saúde.

Através deste documento fica assegurado o seu direito a obter todos os esclarecimentos que considerar necessários. O método utilizado não representa nenhum tipo de intervenção traumática e nenhum dos procedimentos usados oferece riscos à dignidade do participante. Entretanto, como afirmado antes, se a participação neste estudo lhe causar constrangimento ou desconforto emocional, fique à vontade para encerrar sua participação.

\section{Sigilo e privacidade:}

Você tem a garantia de que sua identidade será mantida em sigilo e nenhuma informação será dada a outras pessoas que não façam parte da equipe de pesquisadores. $\mathrm{O}$ conteúdo do diário de campo e as gravações das entrevistas realizadas pela pesquisadora serão armazenadas de forma sigilosa pelos pesquisadores por um período de cinco anos e depois serão excluídas completamente dos arquivos. Durante o período de armazenamento o conteúdo das mesmas não será divulgado. Na divulgação dos resultados desse estudo, sua identidade não será citada ou revelada.

\section{Ressarcimento e Indenização:}

O participante não terá nenhum tipo de despesa ao participar desta pesquisa, bem como nada será pago por sua participação. Você terá a garantia ao direito à indenização diante de eventuais danos decorrentes da pesquisa.

\section{Contato:}

Em caso de dúvidas sobre a pesquisa, você poderá entrar em contato com os pesquisadores Marina Dias Lelis Monteiro e Gustavo Salata Romão, nos telefones (16) 3602- 
2433 ou (17)9.8192-3431, endereço Av. Bandeirantes, 3900, CEP. 14.049-900 - Ribeirão Preto/SP, e-mail: marina_lelis@ usp.com.br.

Em caso de denúncias ou reclamações sobre sua participação e sobre questões éticas do estudo, você poderá entrar em contato com a secretaria do Comitê de Ética do Centro Saúde Escola, da Faculdade de Medicina de Ribeirão Preto, da Universidade de São Paulo, pelo telefone, (16) 3315-0000, e endereço, Rua Teresina, 690, bairro Sumarezinho.

\section{O Comitê de Ética em Pesquisa (CEP).}

O papel do CEP é avaliar e acompanhar os aspectos éticos de todas as pesquisas envolvendo seres humanos. A Comissão Nacional de Ética em Pesquisa (CONEP), tem por objetivo desenvolver a regulamentação sobre proteção dos seres humanos envolvidos nas pesquisas. Desempenha um papel coordenador da rede de Comitês de Ética em Pesquisa (CEPs) das instituições, além de assumir a função de órgão consultor na área de ética em pesquisas

\section{Consentimento livre e esclarecido:}

Após ter recebido esclarecimentos sobre a natureza da pesquisa, seus objetivos, métodos, benefícios previstos, potenciais riscos e o incômodo que esta possa acarretar, aceito participar e declaro estar recebendo uma via original deste documento assinada pelo pesquisador e por mim, tendo todas as folhas por nós rubricadas:

Nome do (a) participante:

Contato telefônico:

E-mail (opcional):

Data:

(Assinatura do participante ou nome e assinatura do seu RESPONSÁVEL LEGAL)

\section{Responsabilidade do Pesquisador:}

Asseguro ter cumprido as exigências da resolução 466/2012 CNS/MS e complementares na elaboração do protocolo e na obtenção deste Termo de Consentimento Livre e Esclarecido. Asseguro, também, ter explicado e fornecido uma via deste documento ao participante. Informo que o estudo foi aprovado pelo CEP perante o qual o projeto foi apresentado. Comprometo-me a utilizar o material e os dados obtidos nesta pesquisa exclusivamente para as finalidades previstas neste documento ou conforme o consentimento dado pelo participante.

Data: 1 
ANEXO C: Parecer consubstanciado do Conselho de Ética

\section{CENTRO DE SAÚDE ESCOLA \\ DA FACULDADE DE MEDICINA DE RIBEIRÃO PRETO -}

\section{PARECER CONSUBSTANCIADO DO CEP}

\section{DADOS DO PROJETO DE PESQUISA}

Título da Pesquisa: A comunicaçäo no contexto das visitas domiciliares: uma investigaçäo das percepçöes de profissionais e usuários na Estratégia Saúde da Família.

Pesquisador: Marina Dias Lelis Monteiro

Área Temática:

Versäo: 2

CAAE: 58059016.3 .0000 .5414

Instituição Proponente: Centro de Saúde Escola - Faculdade de Medicina de Ribeiräo Preto - USP

Patrocinador Principal: Financiamento Próprio

\section{DADOS DO PARECER}

Número do Parecer: 1.715.219

\section{Apresentação do Projeto:}

O acesso das comunidades ao Sistema Único de Saúde no Brasil está sendo ampliado através da Atenção Primária de Saúde e Estratégia Saúde da Família, que preconizam açöes interprofissionais e centradas na pessoa (1). Os modelos de atençäo centrados na pessoa pressupõem a participação ativa dos pacientes e seus familiares nas ações cuidadoras e processos de tomada de decisōes através do aprimoramento das habilidades de comunicação dos profissionais integrantes das equipes de saúde(2). A formação de vínculo entre a comunidade $e$ as equipes de saúde representa um passo crítico nesse processo e pode ser facilitado através de profissionais qualificados em habilidades de comunicaçäo (3). Ainda que algumas habilidades de comunicação apresentem certo componente inato, a maioria dos experts concorda que a habilidade de comunicação apropriada requer treinamento intencional, sistemático e experimental $(6 ; 7)$. Sob perspectivas teóricas, o aprendizado experimental difere do aprendizado pela prática no sentido em que o primeiro é considerado um processo estruturado cíclico cujo objetivo é amplificar o aprendizado através da ativaçäo de conhecimento prévio, prática, reflexão e devolutiva (feedback) que pode se ajustar ao nível individual ou coletivo, no contexto da prática estruturada ou corriqueira $(8 ; 9)$. Neste sentido, a estruturaçäo do treinamento de profissionais de saúde em objetivos e habilidades pré-estabelecidas possibilita a aquisição de

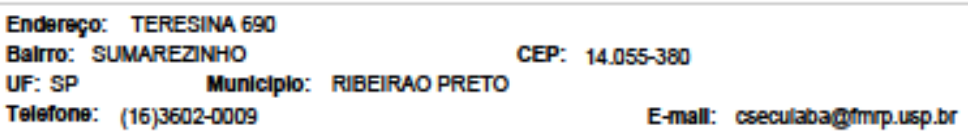




\section{CENTRO DE SAÚDE ESCOLA \\ DA FACULDADE DE MEDICINA Q Poroformo DE RIBEIRÃO PRETO -}

Continusçbo do Parecer. 1.715219

um repertório de estratégias aplicáveis na relação e vinculo com os pacientes (10). Alternativas ao treinamento focado em habilidades pré-estabelecidas incluem o treinamento mobilizado pelas próprias necessidades dos profissionais, levando em consideração suas percepçöes em sua própria relaçäo com os pacientes (12).

No contexto da Saúde da Família, o Agente Comunitário de Saúde (ACS) corresponde a um importante elo de ligação entre os serviços de saúde e a comunidade. Entretanto, diante das condiçőes hierárquicas do sistema de saúde, em sua prática ainda predomina o modelo centrado na doença, prescritivo e fiscalizador.Avaliando as relações dos ACSs com a equipe de saúde e com a comunidade, Cardoso e Nascimento (16)verificaram uma interação insuficiente entre as diferentes categorias profissionais e os segmentos sociais envolvidos, sugerindo a necessidade de uma reflexäo e avaliaçäo do processo de trabalho e formação (continuada e permanente) dos profissionais, com ènfase na qualidade da comunicação entre os diversos atores (17). Em seu trabalho, os ACSs assumem diferentes papéis, ora se posicionando como morador da comunidade, reivindicando direitos sociais, ora atuando como agente de saúde se apropriando do

conhecimento adquirido sobre o processo saúde-doença. Sua forma de comunicação e expressão é influenciada pelos diversos cenários e vivèncias no desempenho de suas funçöes, sendo cobrados pela comunidade tanto por questöes socioeconòmicas (desemprego, maus tratos às crianças) e ambientais (situaçäo do lixo)quanto, questões ligadas ao seu papel nos serviços de saúde (17).Destarte, o contexto de visita domiciliar é adequado para iniciar o trabalho com indivíduos, família e comunidade, pois facilita conhecer simultaneamente as práticas assistenciais e as dinâmicas familiares. A visita domiciliar pode ser realizada de duas formas. A primeira é denominada visita domiciliar "Fim", com objetivos específicos de atuaçäo na atençäo domiciliar terapêutica e visita a pacientes acamados. A segunda é a visita domiciliar "Meio", na qual se realiza a busca ativa pela demanda reprimida, promoçäo e prevençäo da saúde mediante educação em saúde de maneira individualizada. Estas duas abordagens designam um processo dinámico,possibilitando sua implementaçäo na populaçäo alvo, despertando interesse por questöes de saúde, orientações relacionadas às formas de organização do serviço, resolução de problemas e temas gerais de saúde (18).Por se tratar de uma prática realizada por diversos profissionais da área da saúde o conhecimento acerca da dinâmica da visita domiciliar pela ótica e atuaçäo dos diversos membros da equipe de saúde permite propor e reordenar ações de forma a ampliar o potencial de intervençäo desses profissionais, bem como organizar suas práticas para responder às necessidades das famílias no seu lócus de vida. Portanto, neste trabalho pretende-se investigar a dinâmica das visitas domiciliares nos diferentes aspectos da comunicação e relação interpessoal

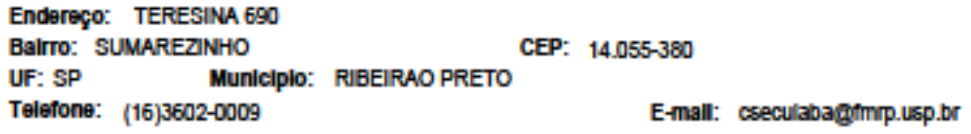




\section{CENTRO DE SAÚDE ESCOLA DE RIBEIRÃO PRETO -}

DA FACULDADE DE MEDICINA QRerosil Prormo

Contlnuş̧⿸丆口 do Parecer. 1.715219

entre os diferentes atores, incluindo os integrantes da equipe de saúde e os membros das famílias visitadas.

\section{Objetivo da Pesquisa:}

Investigar como a comunicação se processa no contexto das visitas domiciliares sob a ótica de profissionais das equipes de Saúde da Família e dos usuários adscritos às equipes.

\section{Avaliação dos Riscos e Beneficios:}

Riscos

A participação dos sujeitos nesta pesquisa não implica em grandes riscos. Os pequenos riscos aos membros das famílias visitadas incluem o desconforto ou constrangimento durante a coleta de dados. Quanto aos integrantes das equipes de saúde, os pequenos riscos se relacionam a possivel interferência em sua rotina de trabalho e ao constrangimento durante as entrevistas. Para minimizar e evitar tais inconveniências, o acompanhamento de visitas será previamente agendado e as entrevistas seräo realizadas em ambiente sigiloso. Caso os participantes sintam-se desconfortáveis durante a entrevista, ela poderá ser interrompida e reagendada, conforme disponibilidade do participante.

\section{Beneficios:}

Ao participar deste estudo os sujeitos estaräo colaborando para obtençäo de informaçöes relevantes sobre a comunicação que se estabelece no contexto das visitas domiciliares e desta forma contribuindo para melhoria da atenção à saúde das famílias pelas equipes na Estratégia Saúde da Família. Além do que os resultados deste estudo seräo importantes para nortear estratégias de ensino e aprendizagem em habilidades de comunicaçäo na área da saúde.

\section{Comentários e Considerações sobre a Pesquisa:}

Este estudo será de cunho qualitativo utilizando o método de observação participante (OP). Será desenvolvido no município de Ribeiräo Preto, interior do estado de Säo Paulo e terá como cenário a Estratégia Saúde da Família(ESF, a qual integra o Nivel Primário, do Sistema Ủnico de Saúde no Brasil. 0 desenvolvimento do projeto de pesquisa ocorrerá nos seis Núcleos Saúde da Família (NSF) do Centro de Atençäo Primária da Faculdade de Medicina de Ribeiräo Preto da Universidade de Säo Paulo (FMRP-USP). localizados no Distrito Oeste do município. Os profissionais da saúde que compõem as equipes dos NSFs,tal como preconiza o Ministério da Saúde, são: o Médico da

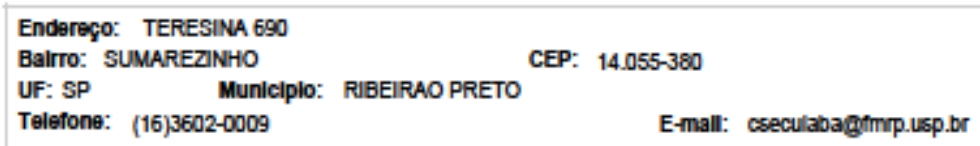




\section{CENTRO DE SAÚDE ESCOLA \\ DA FACULDADE DE MEDICINA Q Plotoformo DE RIBEIRÃO PRETO -}

Contlnusçbo do Parecer. 1.715219

Família, o Enfermeiro da Família, dois Auxiliares de Enfermagem e quatro Agentes Comunitários de Saúde. Além destes, os NSFs em parceria com a USP, recebem médicos residentes do Programa de Medicina de Família e Comunidade e outras residências na

esfera multiprofissional,tais como, nutriçäo,terapia ocupacional,psicologia,farmácia, fonoaudiologia e fisioterapia. Contam também com a participação de docentes e estudantes de várias unidades do Campus da USP. Para tanto, o estudo será realizado com os membros das equipes dos Núcleos Saúde da Família, considerando os seis médicos

de família,as seis enfermeiras e dois a très agentes comunitários de saúde. Em relaçäo aos membros das famílias visitadas estabeleceremos o limite de participantes em função da saturação dos dados obtidos nas entrevistas para formulação de hipóteses e teorias. O recrutamento dos sujeitos da pesquisa será voluntário,mediante convite. Serão convidados os membros da equipe mínima dos NSFs e os integrantes das famílias

visitadas por esses profissionais da saúde. A coleta de dados será realizada mediante seleçäo intencional,ou seja, por conveniência. As visitas domiciliares realizadas pelos membros da equipe de saúde de família atuantes nos NSFs seräo acompanhadas pela pesquisadora, que estará in loco durante o período de coleta de dados. A coleta de dados será realizada em dois períodos distintos, sendo a primeiro correspondente a Observaçäo Participante (OP) e o segundo correspondente a Fase de Entrevistas. A OP será realizada durante o período de três meses (doze semanas), em que a pesquisadora deverá acompanhar a rotina de visitas domiciliares dos membros da equipe de saúde da família registrando informaçōes e percepções no diário de campo com ênfase nos aspectos concernentes a comunicação e relaçäo interpessoal. Para tanto, serão acompanhadas as visitas realizadas pelos Médicos de Família, os Enfermeiros de Família e os ACSs das equipes de saúde. Durante o período de coleta de dados da OP, a pesquisadora deverá acompanhar, em média, oito visitas domiciliares em cada NSF. Os dados obtidos na OP seräo registrados no diário de campo e posteriormente analisados. Após o período de OP. seräo realizadas entrevistas semi-estruturadas com todos os integrantes da equipe de saúde dos NSFs e com os membros das famílias visitadas, investigando suas vivências e percepções sobre comunicaçäo e relaçäo interpessoal no contexto das visitas domiciliares. Para tanto a pesquisadora deverá questionar a cada entrevistado sobre suas percepções em relaçäo à forma, qualidade, facilitadores e barreiras à comunicação interpessoal durante as visitas domiciliares. Especificamente para os membros das equipes de saúde também será questionado sobre suas percepções em relaçäo ao papel dos outros profissionais no contexto das visitas domiciliares. As entrevistas seräo gravadas em dispositivo eletrônico de áudio para posterior transcriçäo e análise de seu conteúdo. A partir da

Endereço: TERESINA 690

BalrTO: SUMAREZINHO CEP: $14.055-380$

UF: SP MUnICIPIO: RIBEIRAO PRETO

Telefone: (16)3602-0009

E-mall: cseculabagfmr.usp.br 


\section{CENTRO DE SAÚDE ESCOLA \\ DA FACULDADE DE MEDICINA Plotoformo DE RIBEIRÃO PRETO -}

Contlinusçlo do Parecer. 1.715219

análise dos dados transcritos das entrevistas será possível entender os princípios e crenças relacionados à comunicaçäo e relação interpessoal nas visitas domiciliares.

\section{Consideraçöes sobre os Termos de apresentaģão obrigatória:}

A folha e Rosto para a pesquisa envolvendo seres humanos foi assinada pelo pesquisador e pelo responsável da instituiçäo proponente. Os pesquisadores apresentam a autorizaçäo das Unidades selecionadas para a pesquisa. Há cronograma anexado em arquivo separado na plataforma. O TCLE para profissionais e usuários estäo descritos em linguagem acessiva, em forma de convite garantindo a participação e desistência do projeto. Aos respondentes é garantido o sigilo de suas respostas e possibilidade de desistência sem prejuizos.

\section{Recomendaçöes:}

Os pesquisadores incluíram riscos mínimos para a realização da pesquisa nas informaçỏes básicas do Projeto e nos TCLE(s)conforme recomendaçäo em parecer anterior. Também consta cronograma em anexo conforme recomendação da Carta cirular CONEP 061/2012.

Conclusöes ou Pendências e Lista de Inadequaçöes:

Não há pendências. Aprovado.

Consideraçöes Finais a critério do CEP:

Acatado o parecer do relator de aprovar o projeto.

Este parecer foi elaborado baseado nos documentos abaixo relacionados:

\begin{tabular}{|c|c|c|c|c|}
\hline Tipo Documento & Arquivo & Postagem & Autor & Situaçäa \\
\hline $\begin{array}{l}\text { Informações Básicas } \\
\text { do Projeto }\end{array}$ & $\begin{array}{l}\text { PB_INFORMAÇÖES_BÁSICAS_DO_P } \\
\text { ROJETO_760062.pdf }\end{array}$ & $\begin{array}{c}25 / 08 / 2016 \\
20: 09: 47\end{array}$ & & Aceito \\
\hline Outros & Cronograma_Pesquisa.pdf & $\begin{array}{c}25 / 08 / 2016 \\
20: 09: 22 \\
\end{array}$ & \begin{tabular}{|l|} 
Marina Dias Lelis \\
Monteiro \\
\end{tabular} & Aceito \\
\hline $\begin{array}{l}\text { TCLE / Termos de } \\
\text { Assentimento / } \\
\text { Justificativa de } \\
\text { Ausência } \\
\end{array}$ & TCLE_Usuarios.pdf & $\begin{array}{c}25 / 08 / 2016 \\
20: 08: 34\end{array}$ & $\begin{array}{l}\text { Marina Dias Lelis } \\
\text { Monteiro }\end{array}$ & Aceito \\
\hline $\begin{array}{l}\text { TCLE / Termos de } \\
\text { Assentimento / } \\
\text { Justificativa de } \\
\text { Ausência } \\
\end{array}$ & TCLE_Profissionais.pdf & $\begin{array}{c}25 / 08 / 2016 \\
20: 08: 20\end{array}$ & $\begin{array}{l}\text { Marina Dias Lelis } \\
\text { Monteiro }\end{array}$ & Aceito \\
\hline
\end{tabular}

Endereģo: TERESINA 690

BalrTO: SUMAREZINHO MUN: $14.055-380$
UF: SP $\quad$ MUnICIPIO: RIBEIRAO PRETO

Telefone: (16)3602-0009

E-mall: cseculabaghmp.usp.br 


\section{CENTRO DE SAÚDE ESCOLA \\ DA FACULDADE DE MEDICINA DE RIBEIRÃO PRETO -}

Conthnuaçbo do Parecer. 1.715.219

\begin{tabular}{|l|l|c|l|c|}
\hline $\begin{array}{l}\text { Projeto Detalhado I } \\
\text { Brochura } \\
\text { Investigador }\end{array}$ & Projeto_Detalhado.pdf & $\begin{array}{c}25 / 08 / 2016 \\
20: 07: 06\end{array}$ & $\begin{array}{l}\text { Marina Dias Lelis } \\
\text { Monteiro }\end{array}$ & Aceito \\
\hline Folha de Rosto & Folha_Rosto_pdf & $\begin{array}{c}22 / 07 / 2016 \\
11: 20: 39\end{array}$ & $\begin{array}{l}\text { Marina Dias Lelis } \\
\text { Monteiro }\end{array}$ & Aceito \\
\hline Outros & $\begin{array}{l}\text { Autorizacao_das_Instituicoes_Participan } \\
\text { tes.pdf }\end{array}$ & $\begin{array}{c}22 / 07 / 2016 \\
11: 20: 20\end{array}$ & $\begin{array}{l}\text { Marina Dias Lelis } \\
\text { Monteiro }\end{array}$ & Aceito \\
\hline
\end{tabular}

Situação do Parecer:

Aprovado

Necessita Apreciaçäo da CONEP:

Näo

RIBEIRAO PRETO, 06 de Setembro de 2016

Assinado por:
LAÉRCIO JOEL FRANCO
(Coordenador)

(Coordenador)

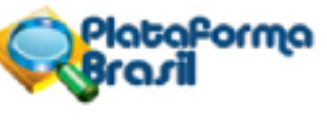

